\title{
Systemic lupus erythematosus (SLE) in childhood: analysis of clinical and immunological findings in 34 patients and comparison with SLE characteristics in adults
}

Josep Font, Ricard Cervera, Gerard Espinosa, Lucio Pallarés, Manel Ramos-Casals, Sònia Jiménez, Mario García-Carrasco, Luís Seisdedos, Miguel Ingelmo

\begin{abstract}
Objective-To define the pattern of disease expression in patients with childhood onset systemic lupus erythematosus (SLE).

Methods-Prospective analysis of clinical manifestations and immunological features of 34 patients in whom the first manifestations appeared in childhood from a series of 430 unselected patients with SLE.
\end{abstract}

Results-Thirty one (91\%) patients from the childhood onset group were female and three male (9\%) (ratio female/male, $10 / 1$, with no difference compared with the adult onset group). Mean age of this group at disease onset was 11 years (range 5-14) compared with 32 years (15-48) for the remaining patients. The childhood onset patients more often had nephropathy $(20 \% v 9 \%$ in adult onset SLE, $p=0.04$;
Systemic lupus erythematosus (SLE) predominantly affects young women in reproductive age. ${ }^{1}$ In $10-20 \%$ of patients, however, the diagnosis is made for the first time in childhood. ${ }^{2-6}$

Several investigators have reported that age at onset has a modifying effect on disease expression. This is important because examination of more homogeneous subsets, such as childhood onset patients, may allow for earlier diagnosis, better treatment, and more accurate prognosis. It has been noted that certain features of SLE usually associated with severity, such as nephritis or central nervous system dysfunction, are more common in patients with childhood onset SLE. In addition, serological abnormalities have also been reported to be different in childhood patients. ${ }^{2-6}$ However, the small number of patients that have been analysed in the different series, the disparity in selection criteria for patient inclusion, the age limits adopted, or the definition of the variables make comparison of findings in previous reports very difficult.

In this study, to better define the pattern of disease expression in childhood onset SLE patients, we have prospectively analysed the clinical manifestations and immunological features of 34 patients in whom the first manifestations appeared in the childhood from a series of 430 unselected patients with SLE.

\section{Methods}

PATIENT SELECTION

We studied prospectively 430 patients with SLE who were seen consecutively either as inpatients or outpatients between 1980 and 1995 and who were followed up by the same attending physicians (JF, RC, LP, MI). All were white and met the American College of Rheumatology (formerly American Rheumatism Association, ARA) ${ }^{7}$ revised criteria for SLE. In $34(8 \%)$ the onset of disease, defined as the initial manifestation clearly attributable to SLE, occurred before the age of 14, and they represent the childhood onset group described in this report. The remaining 396 (92\%) patients presented the initial manifestations after the age of 14, and they represent the adult onset group. All had medical histories documented and underwent medical interview as well as routine general physical examination by a qualified internist. A serum sample from each patient was collected for the immunological tests. Clinical and serological characteristics of all these patients were collected in a protocol

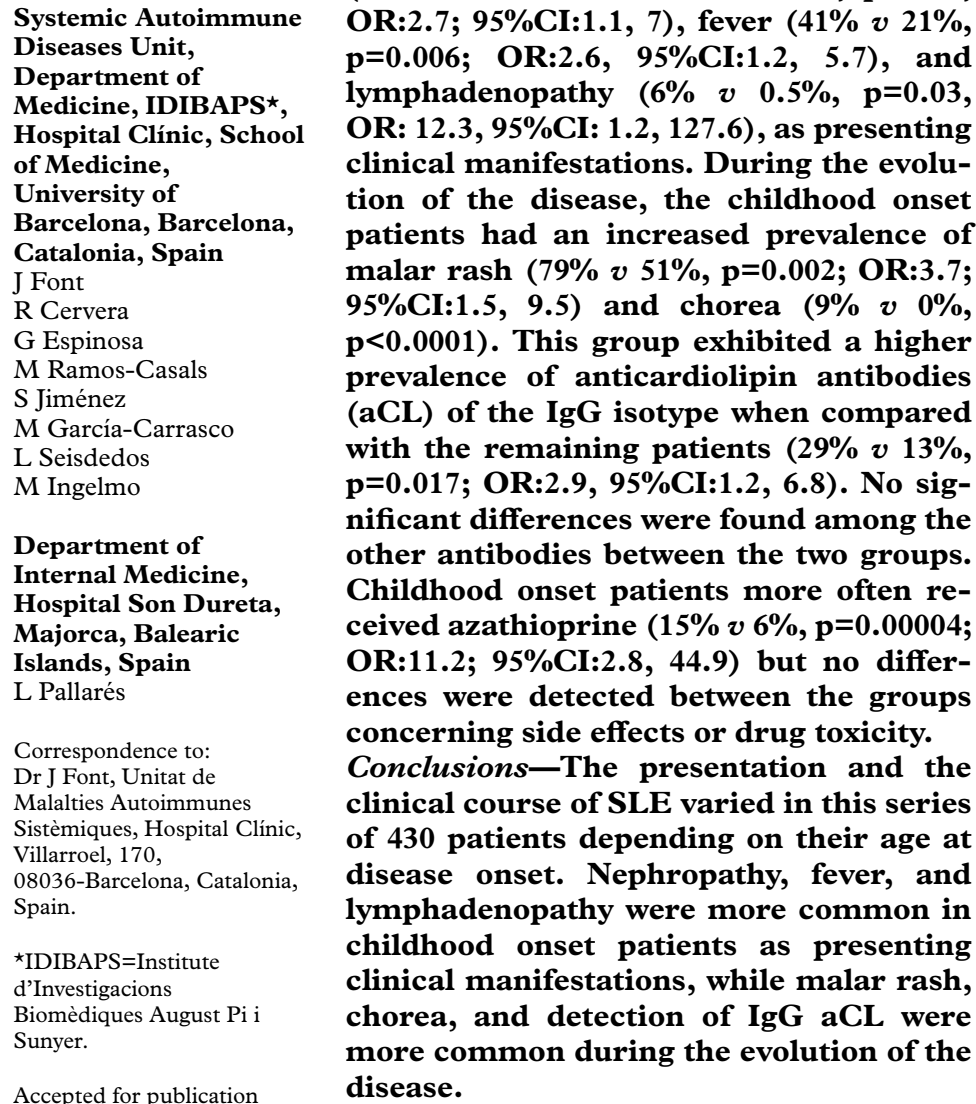

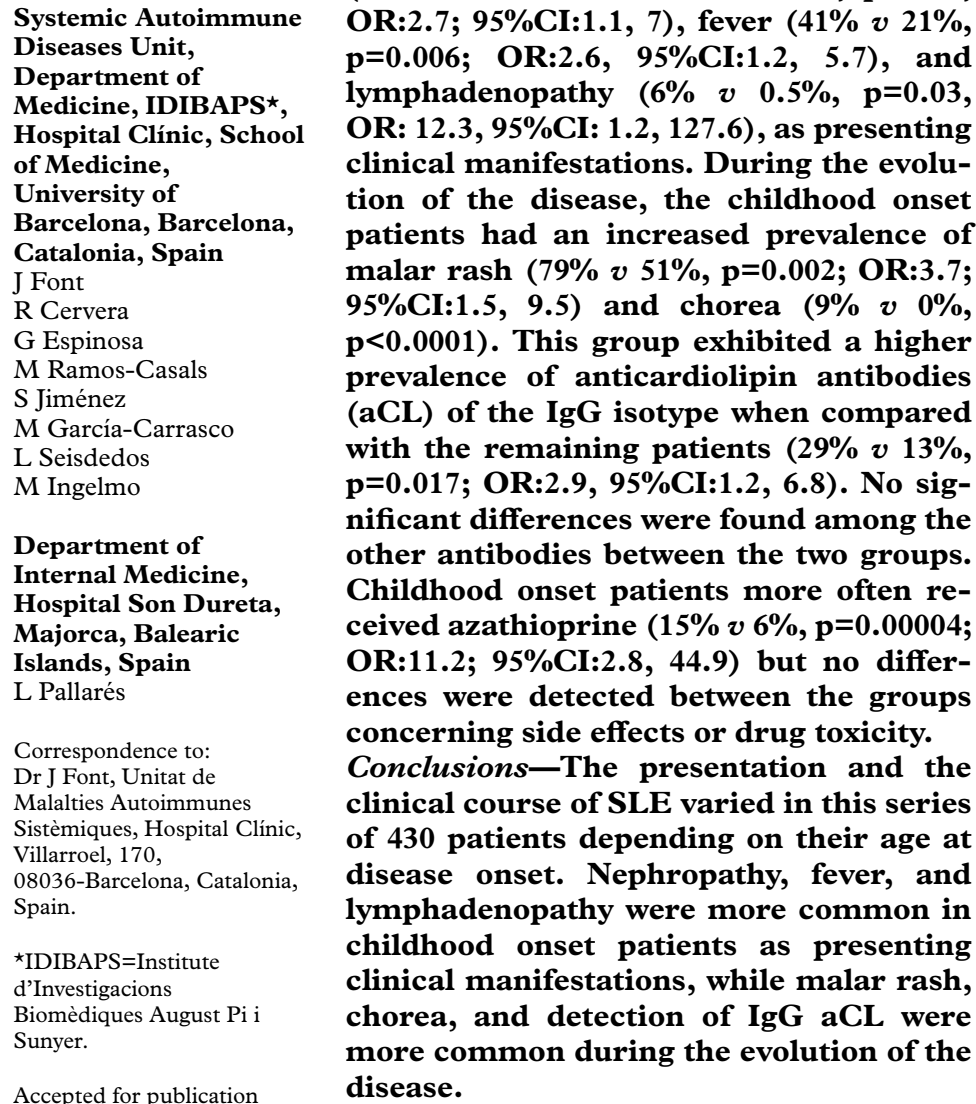

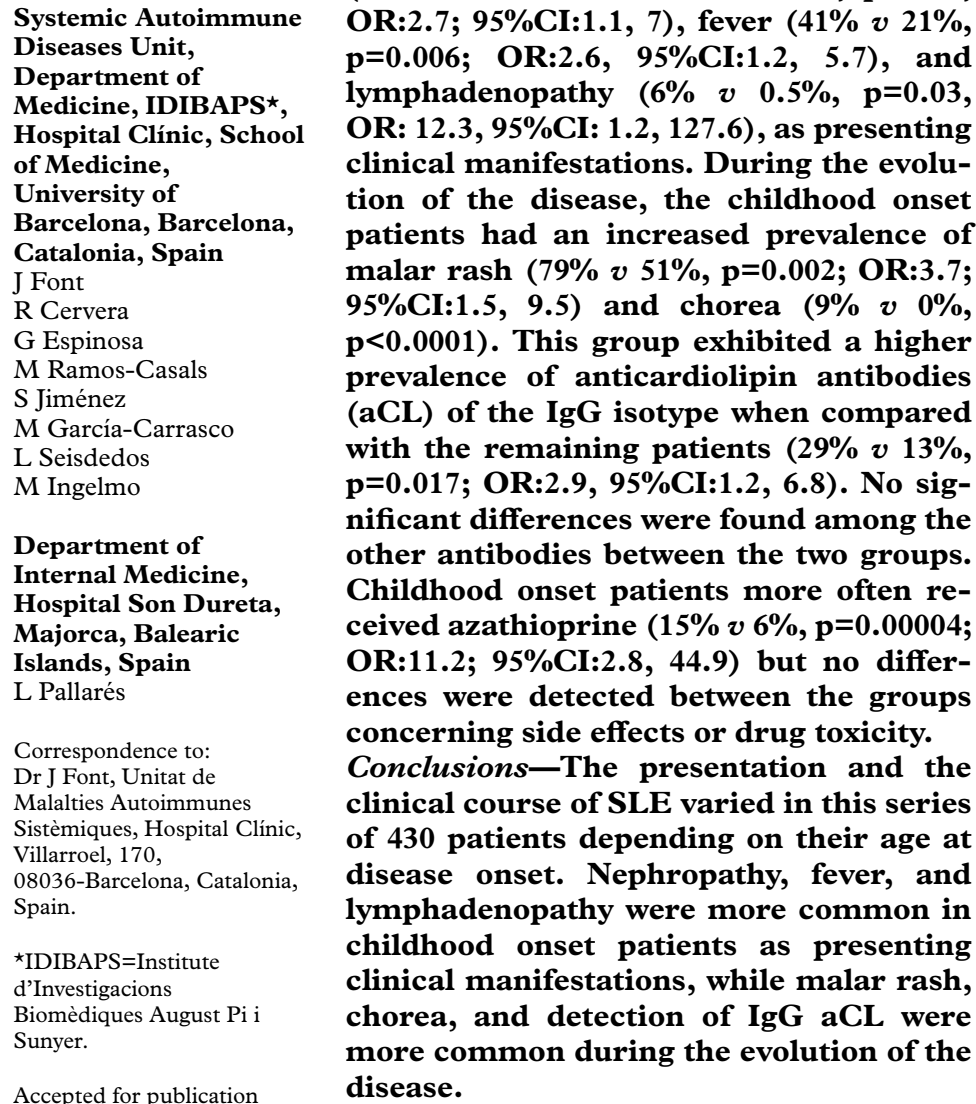

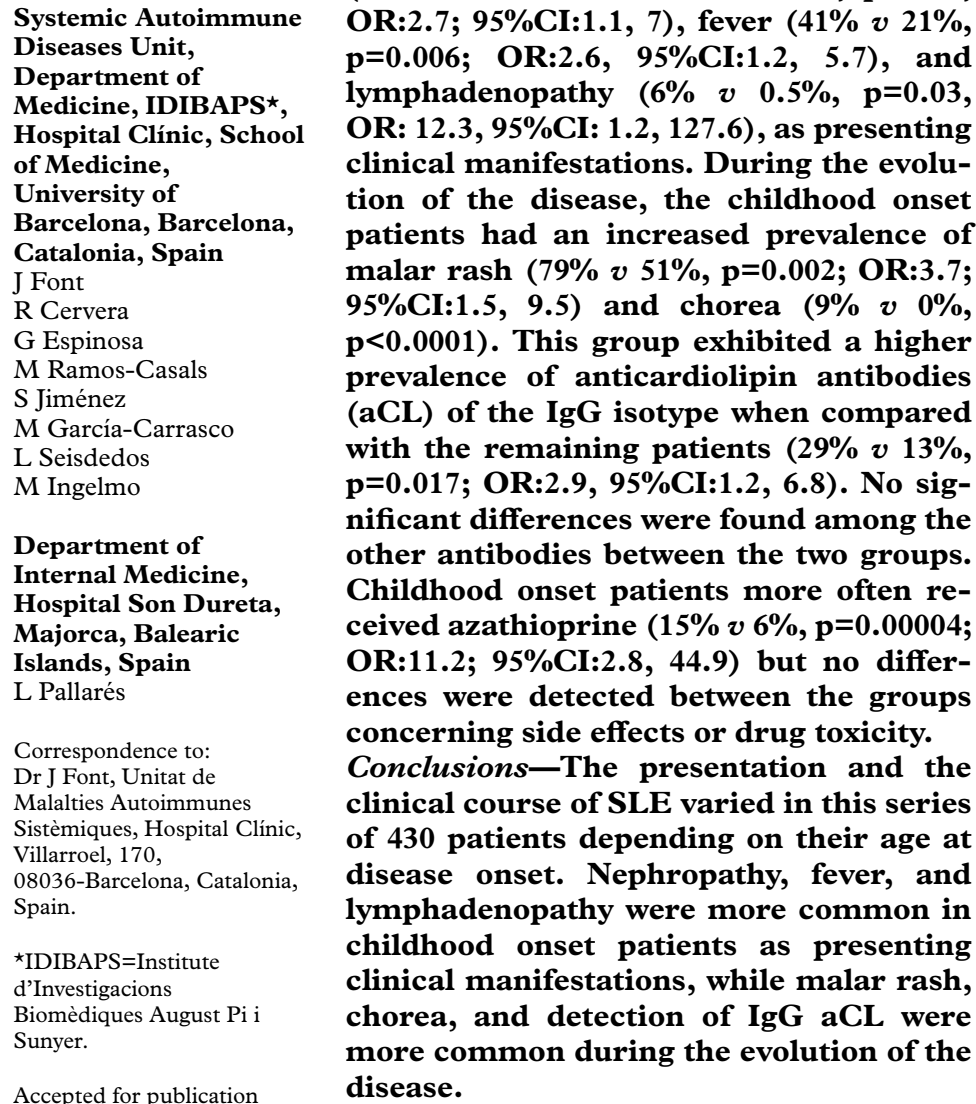

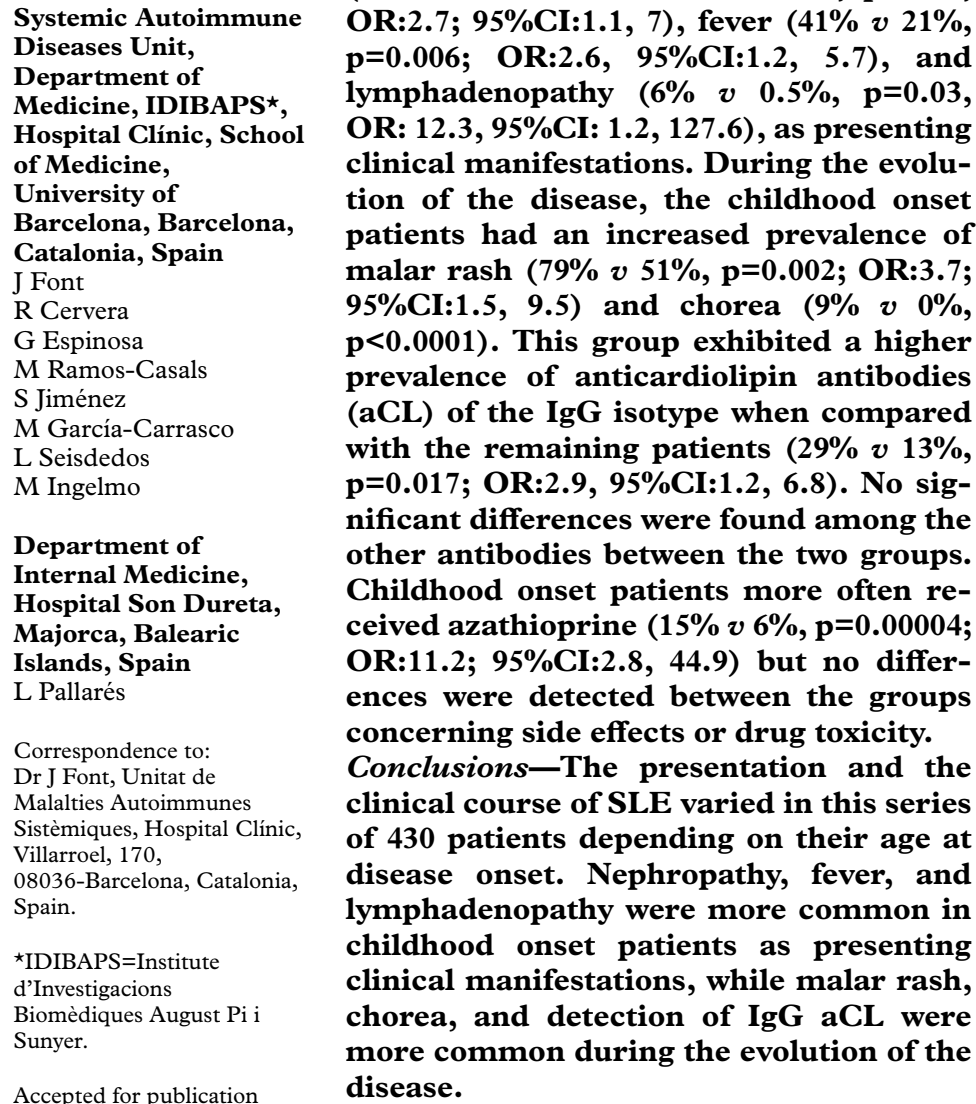

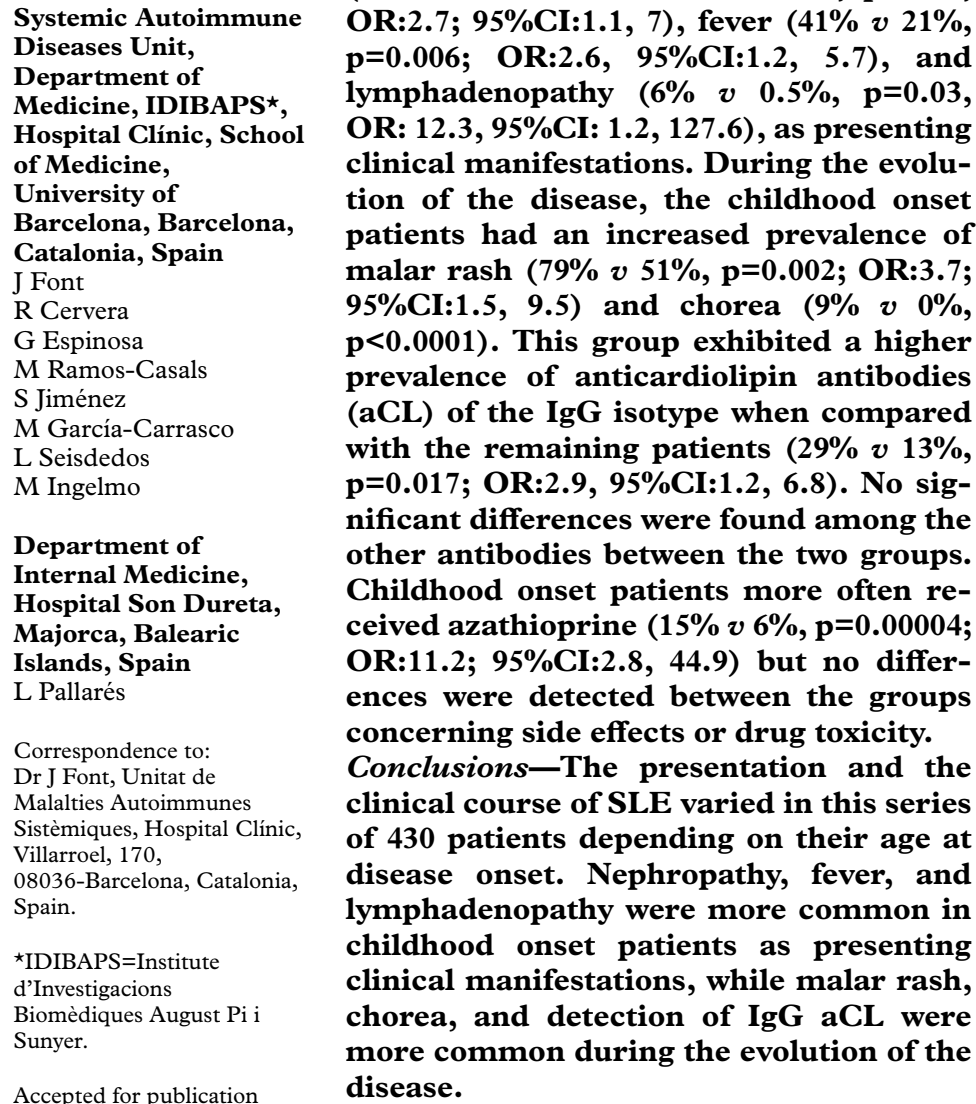

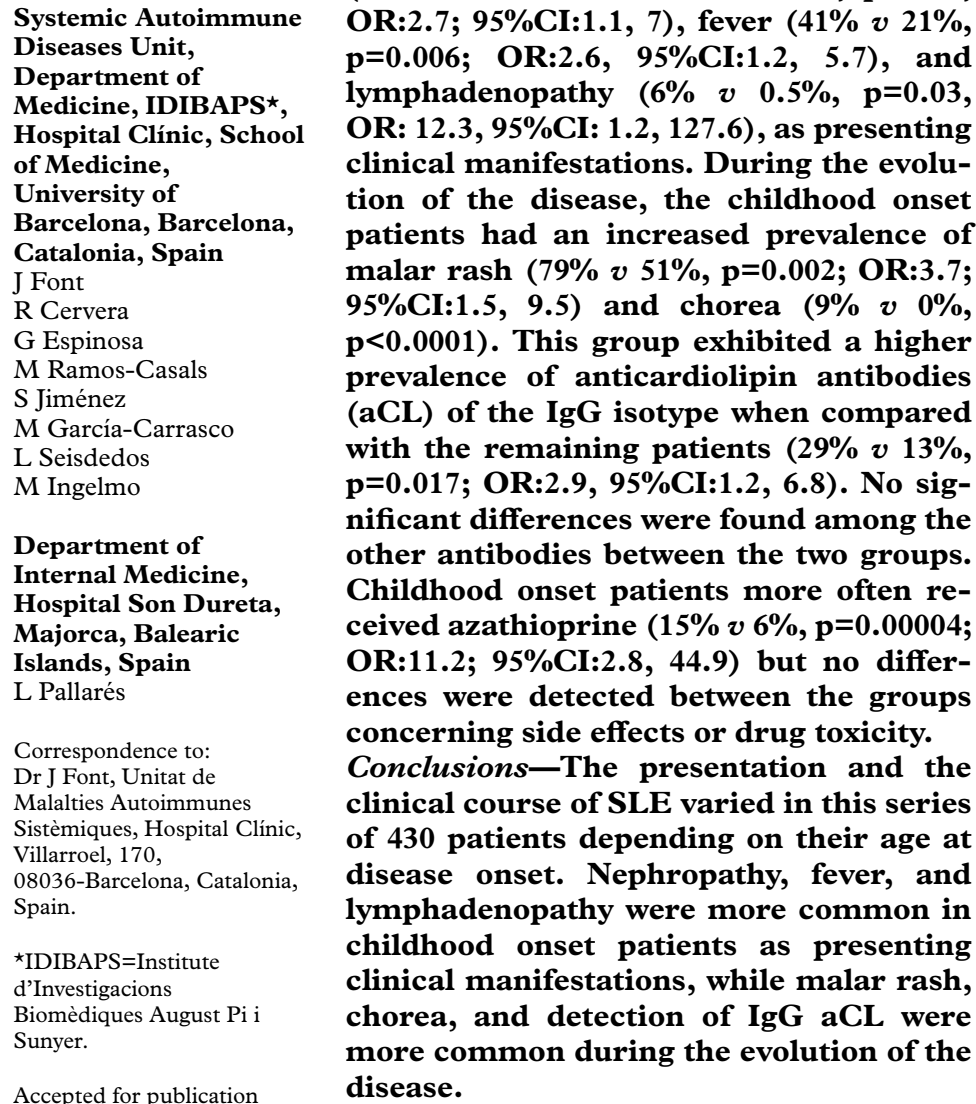

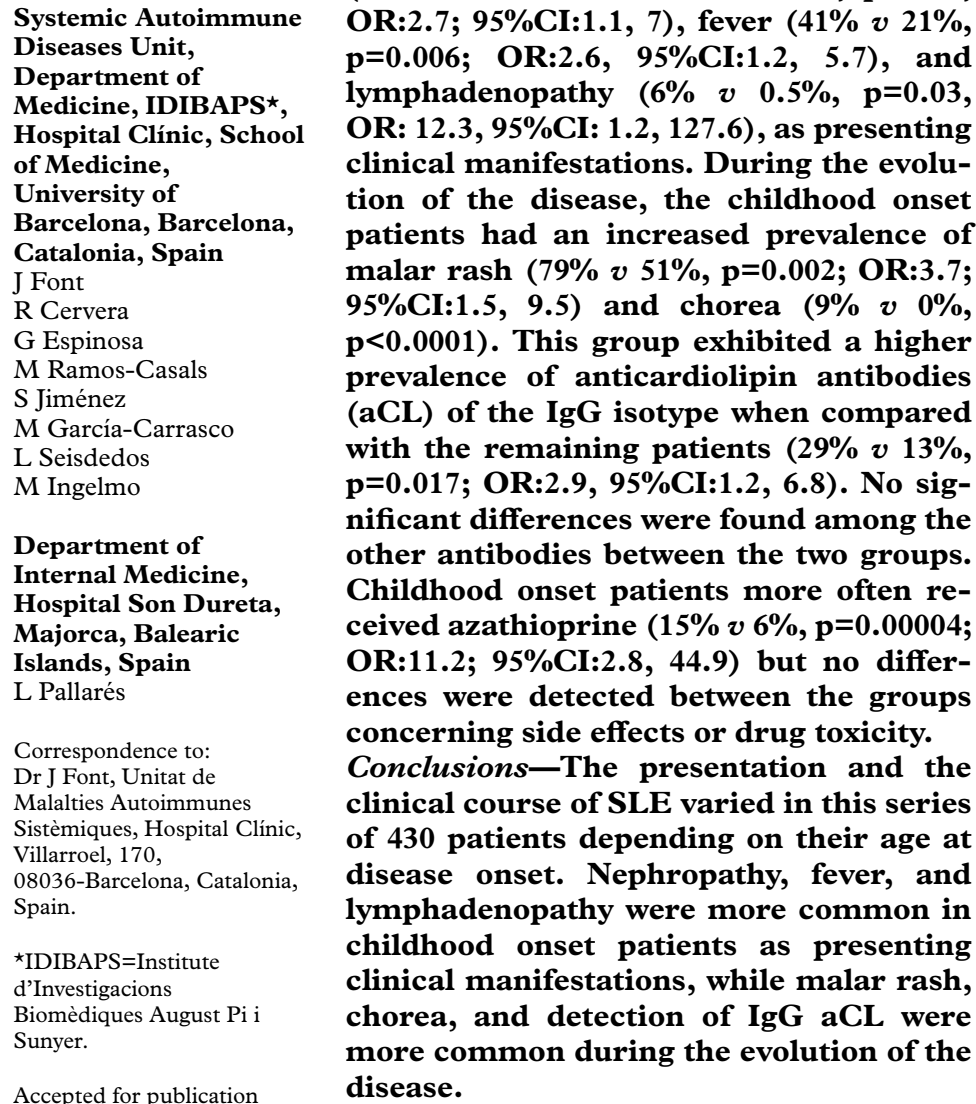

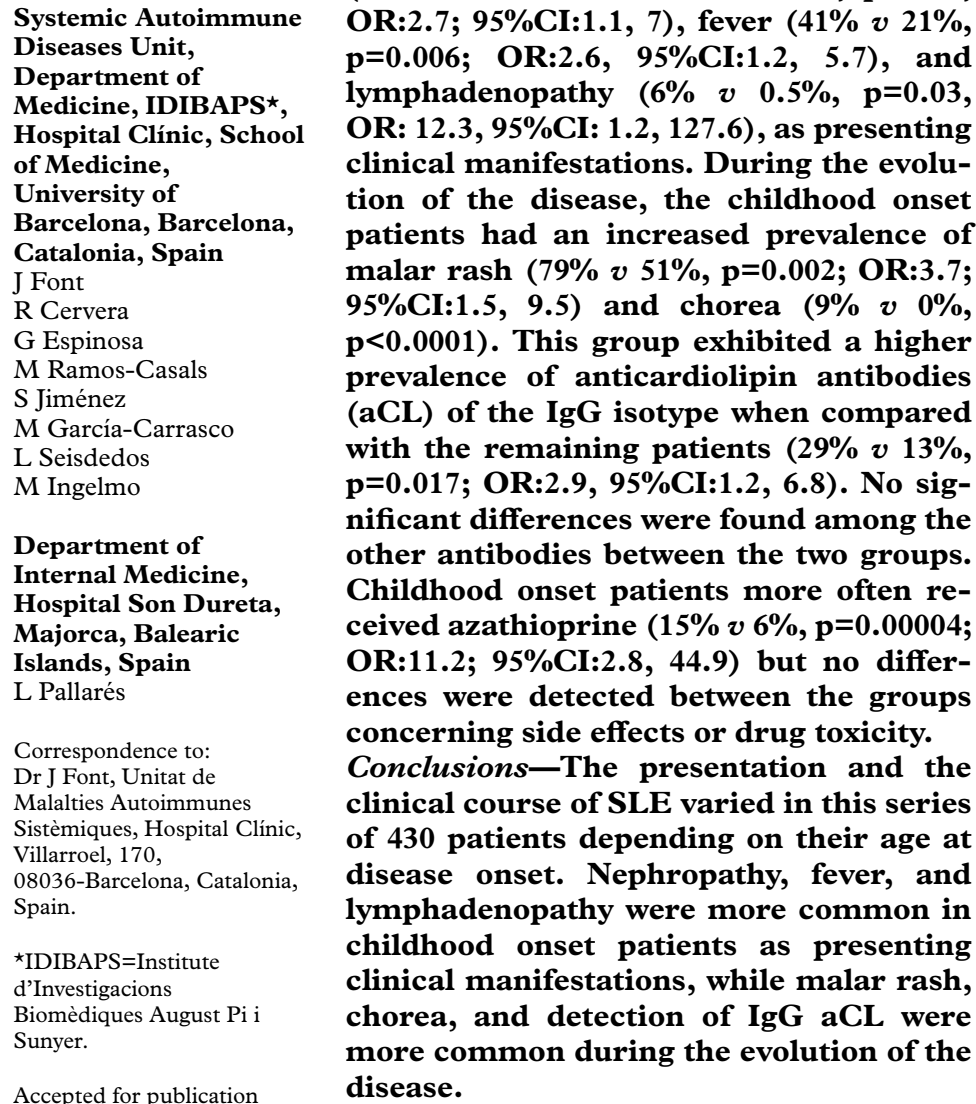

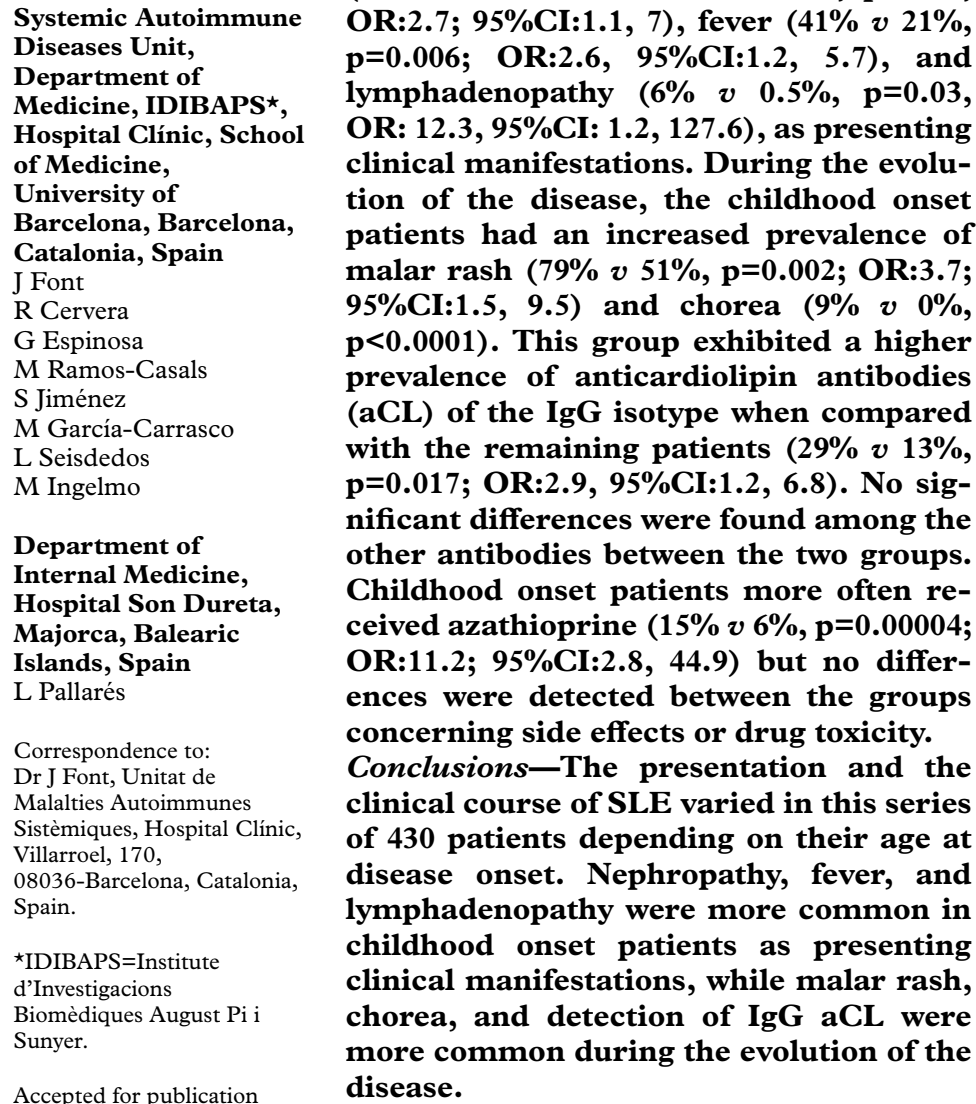

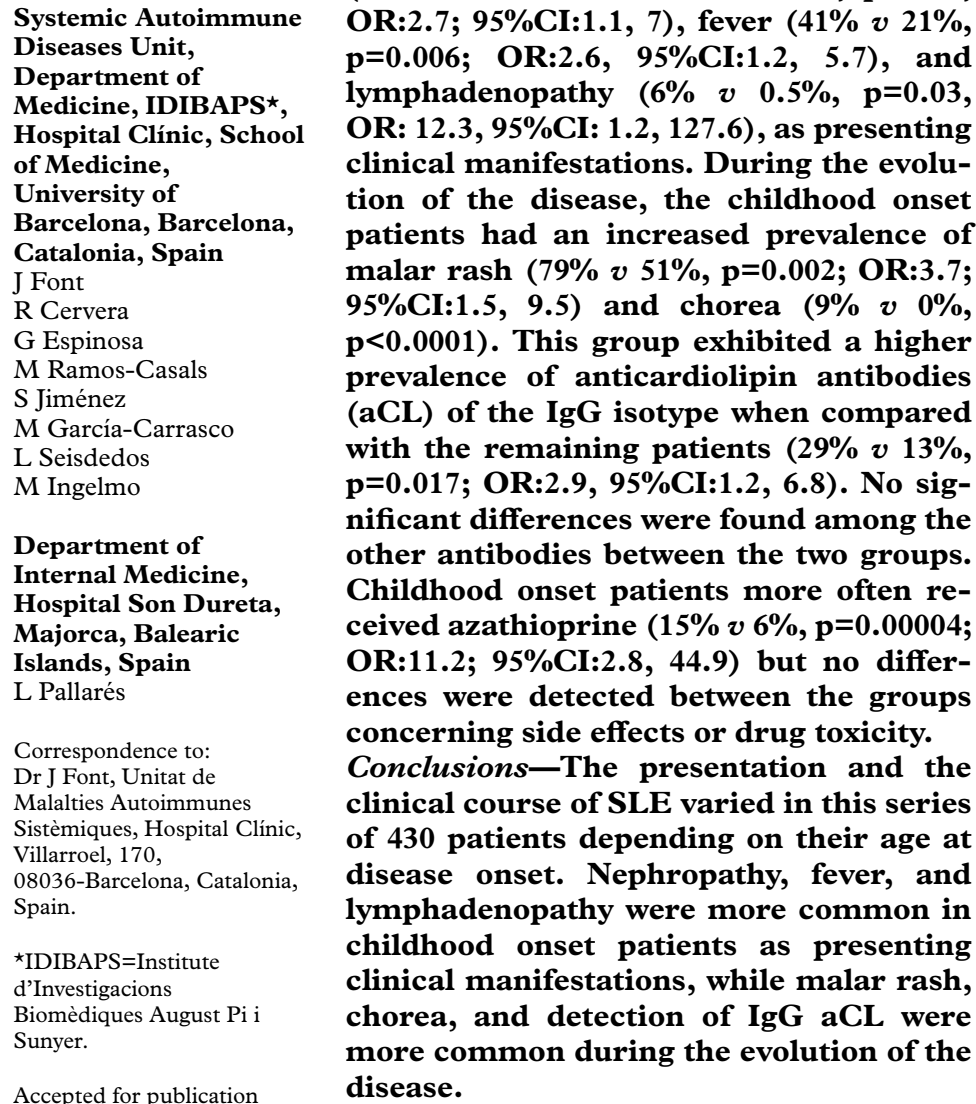

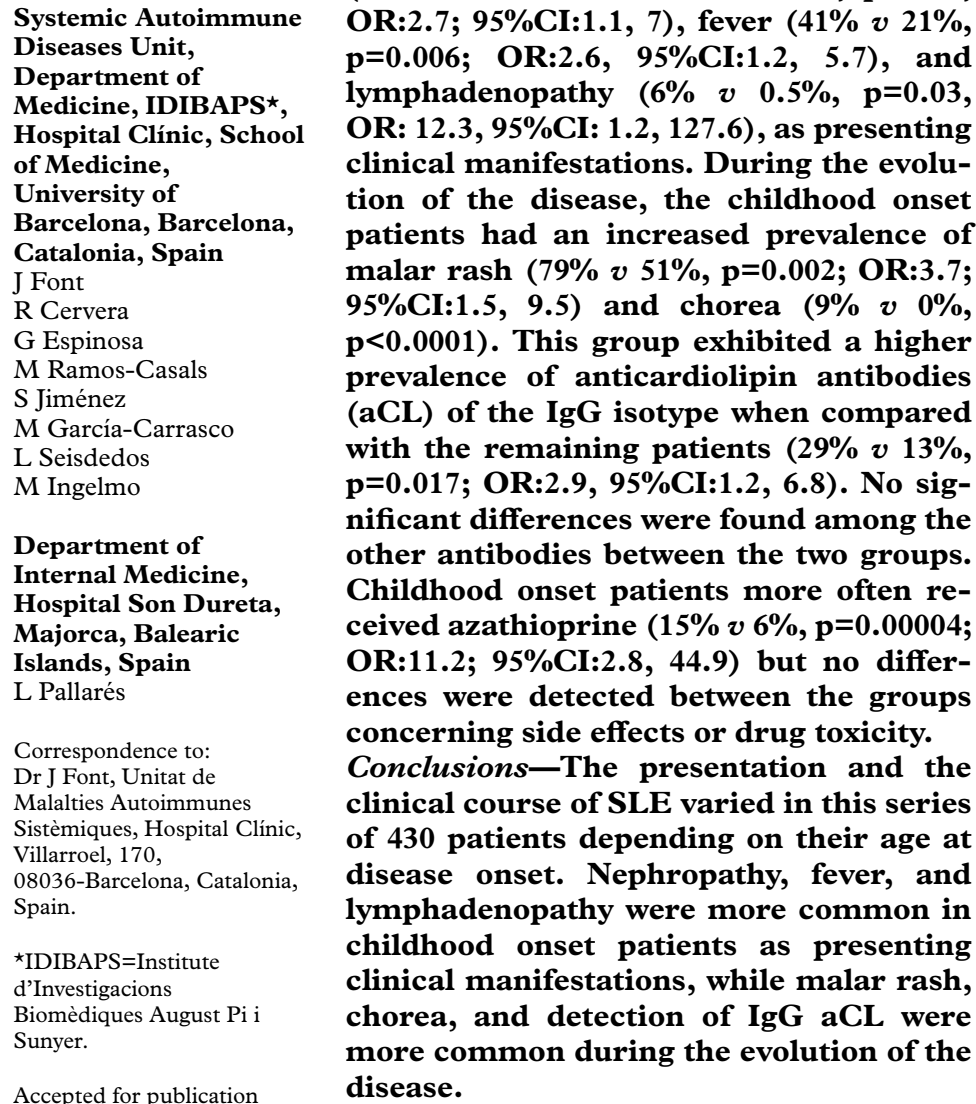

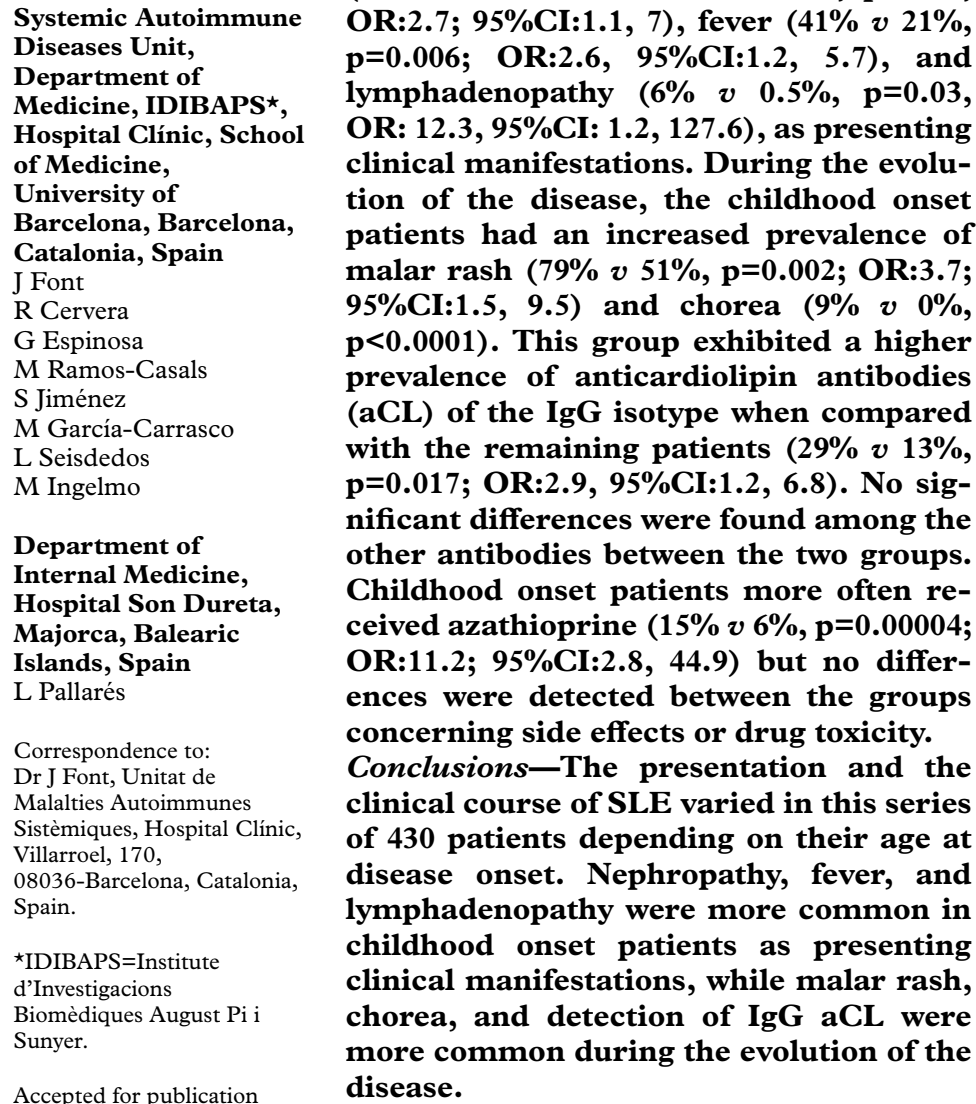

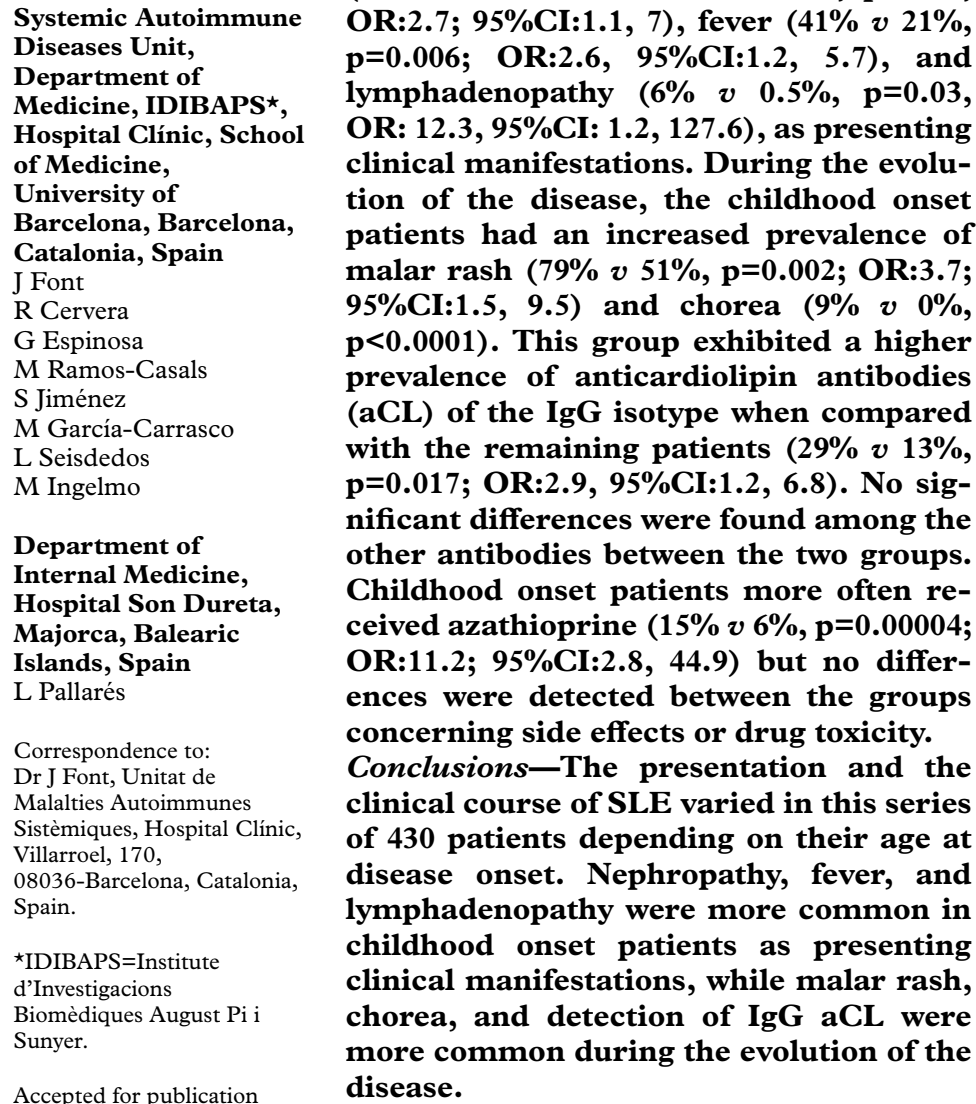

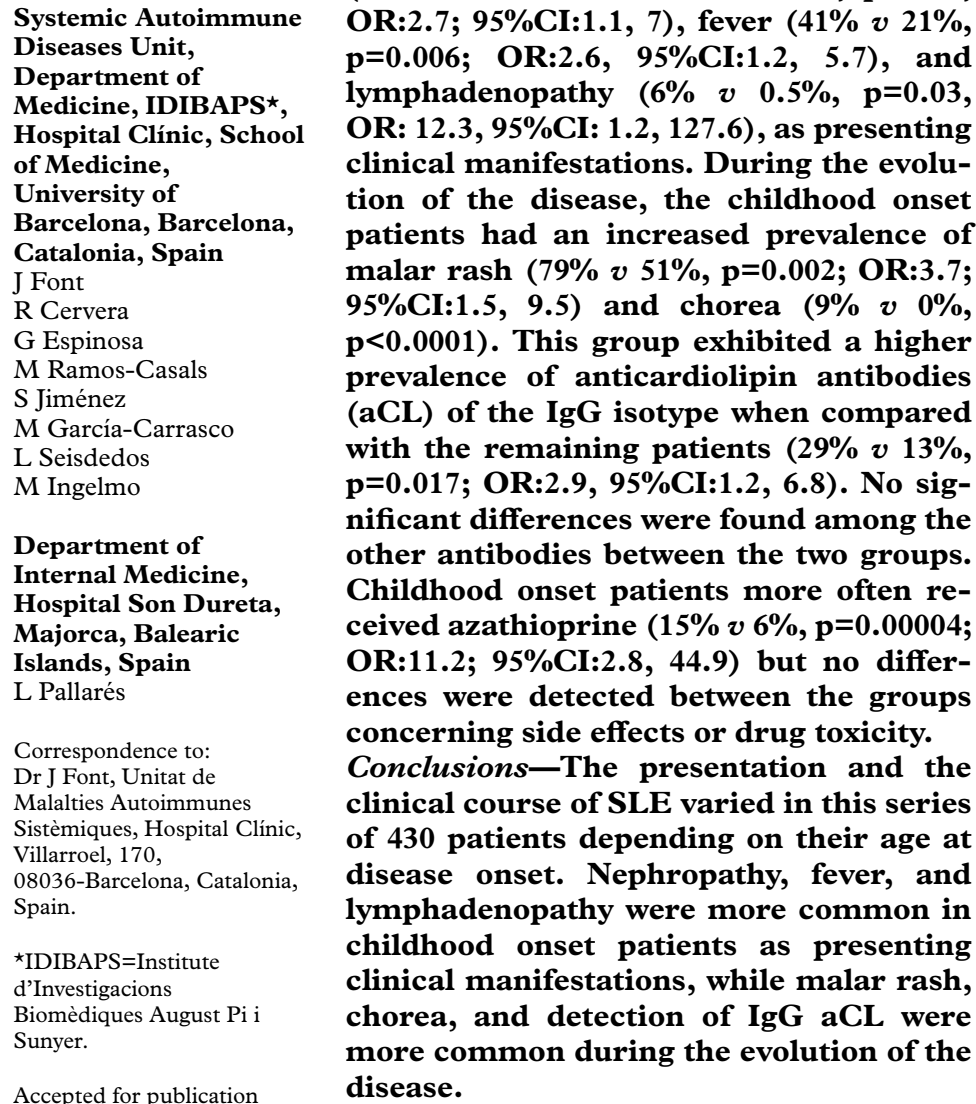

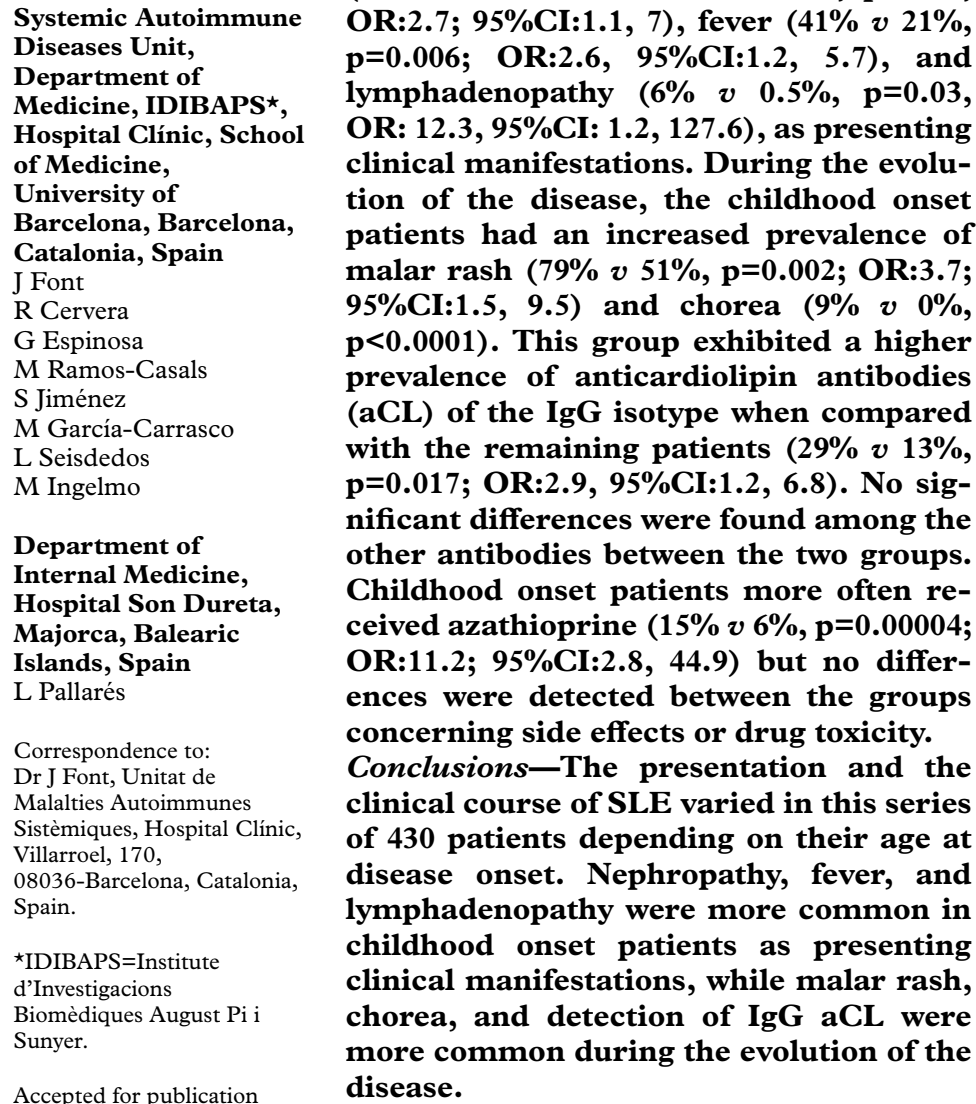

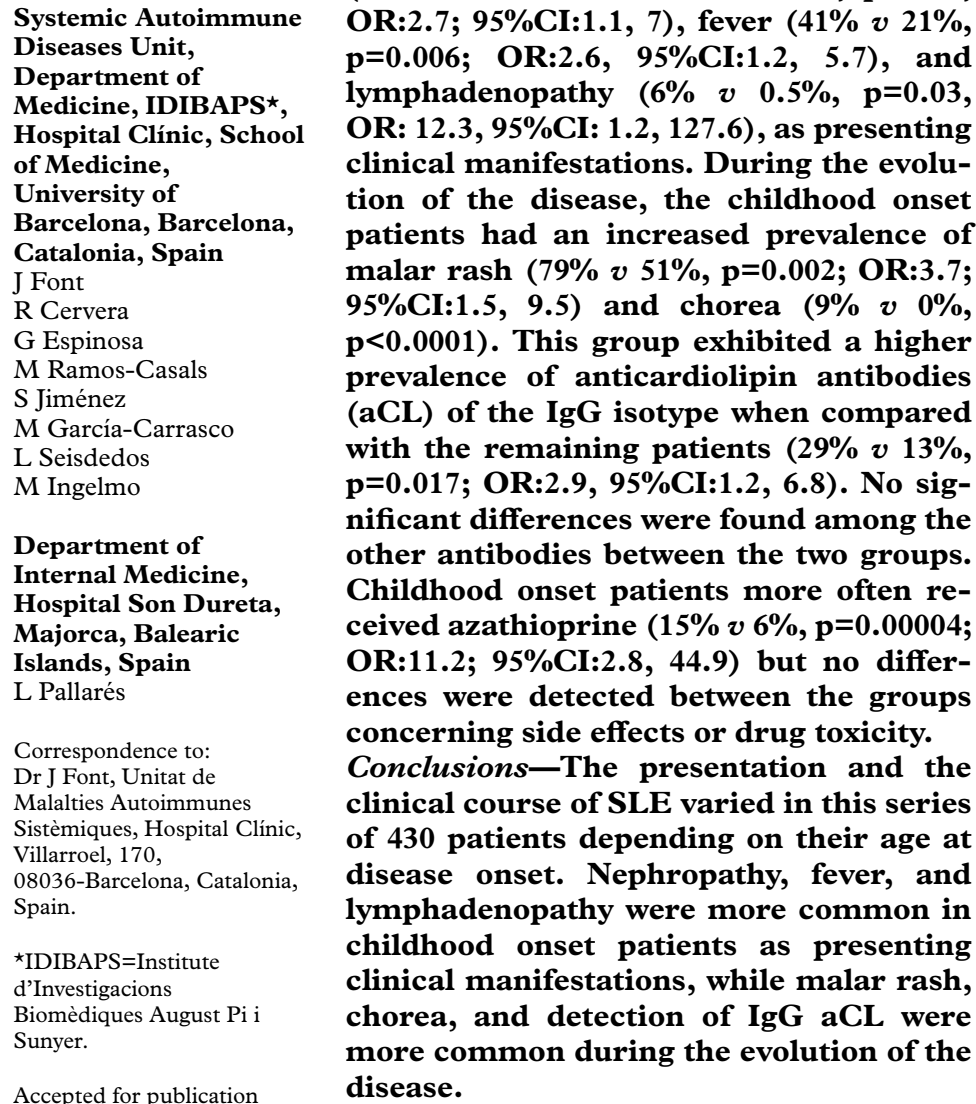

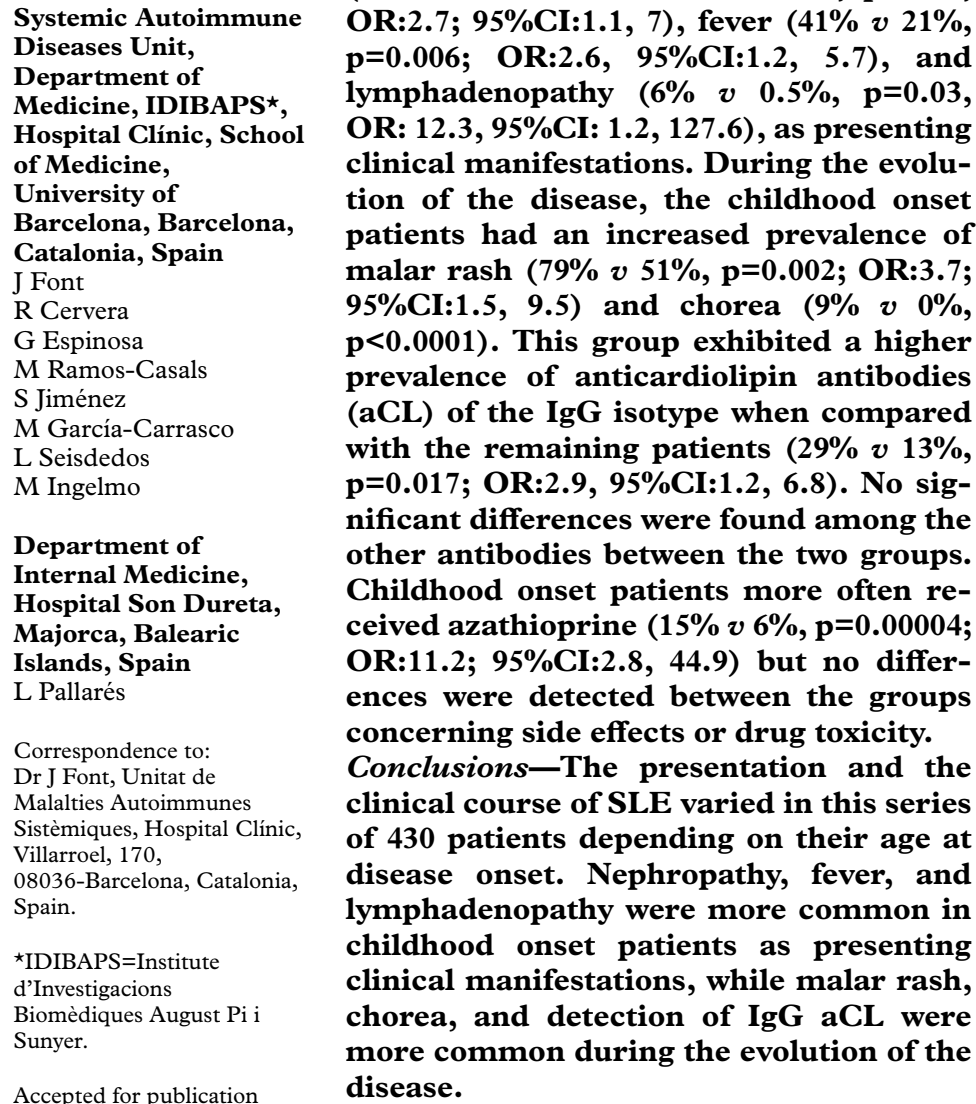

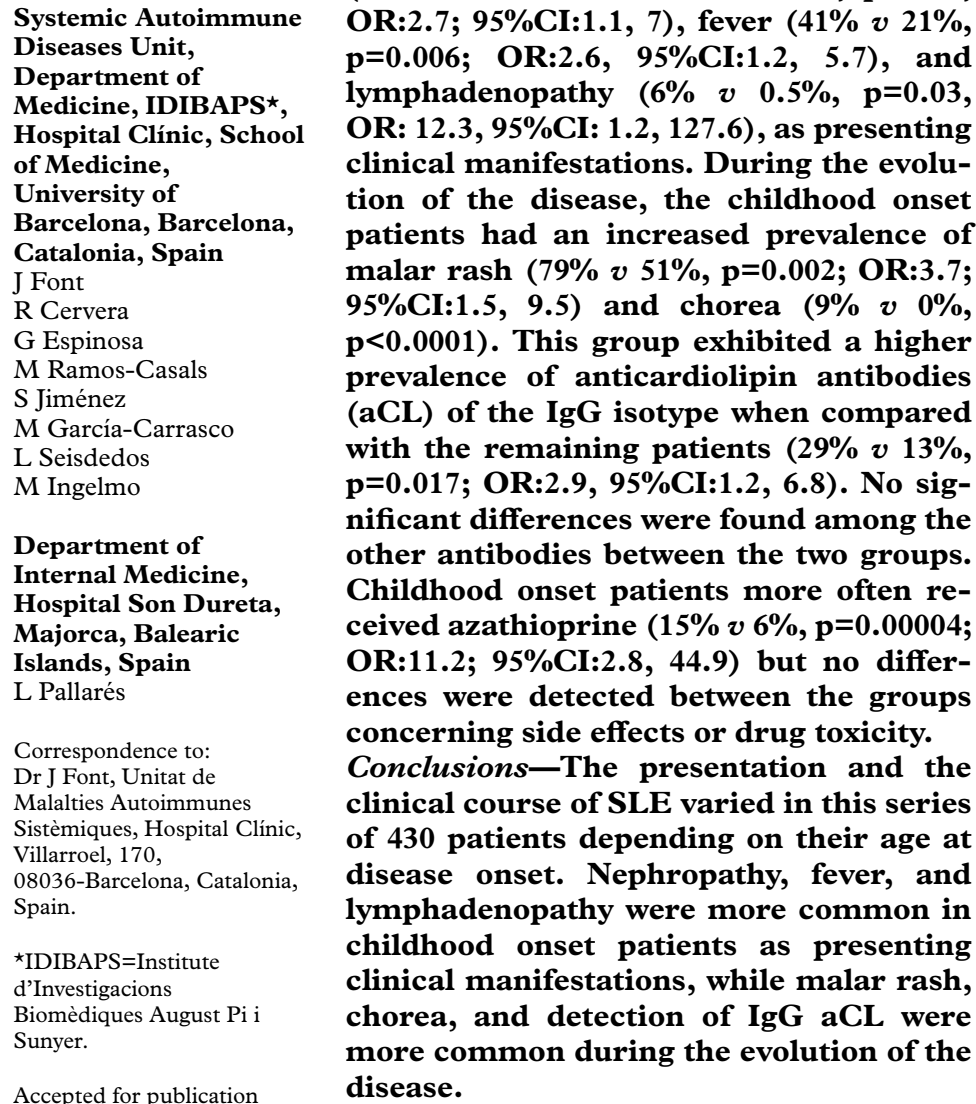

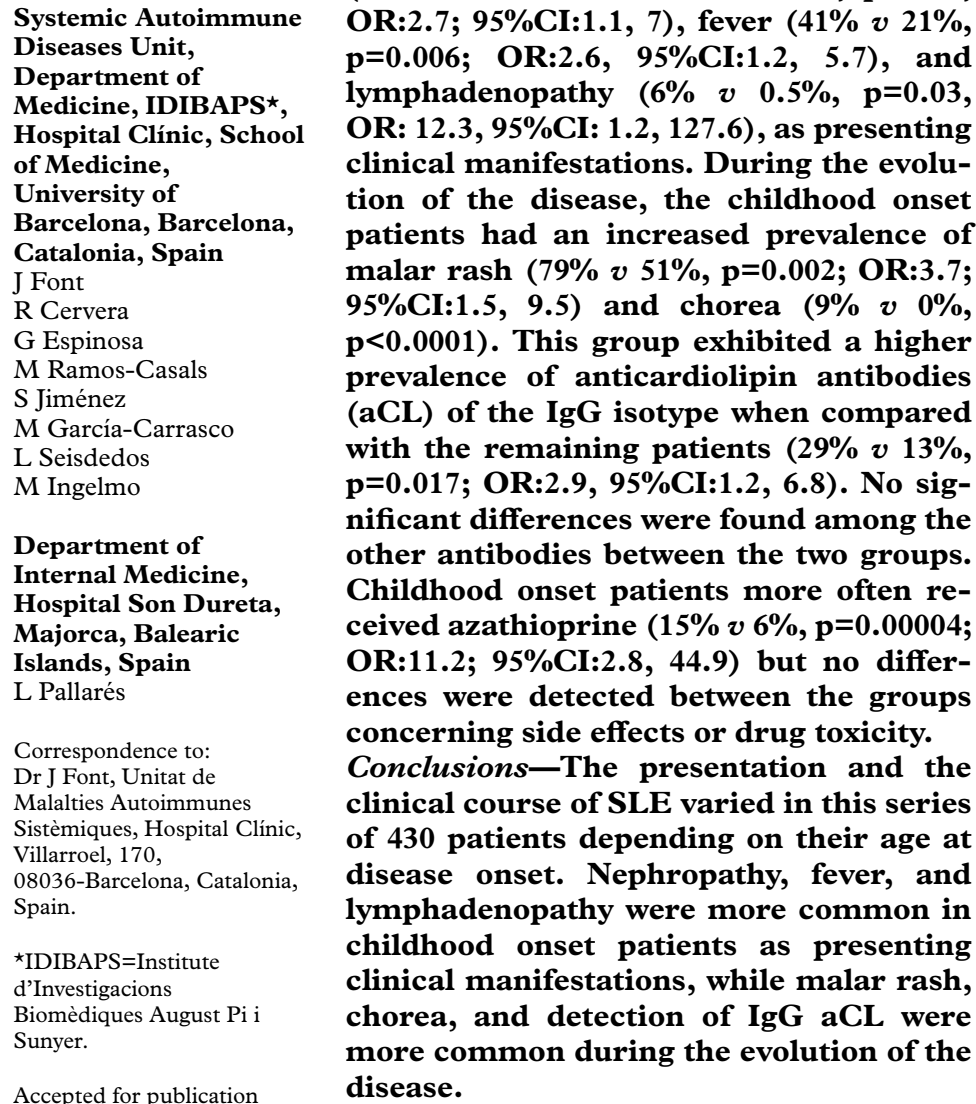

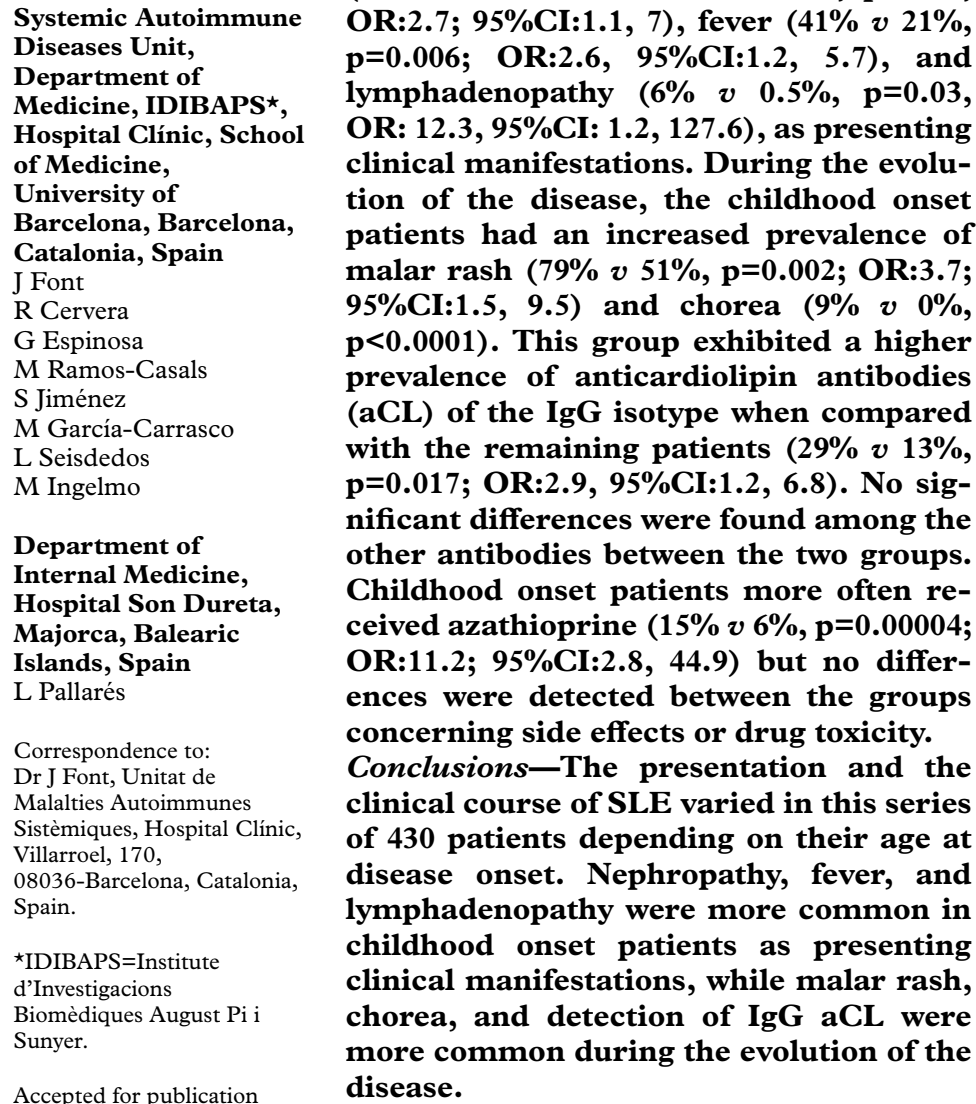

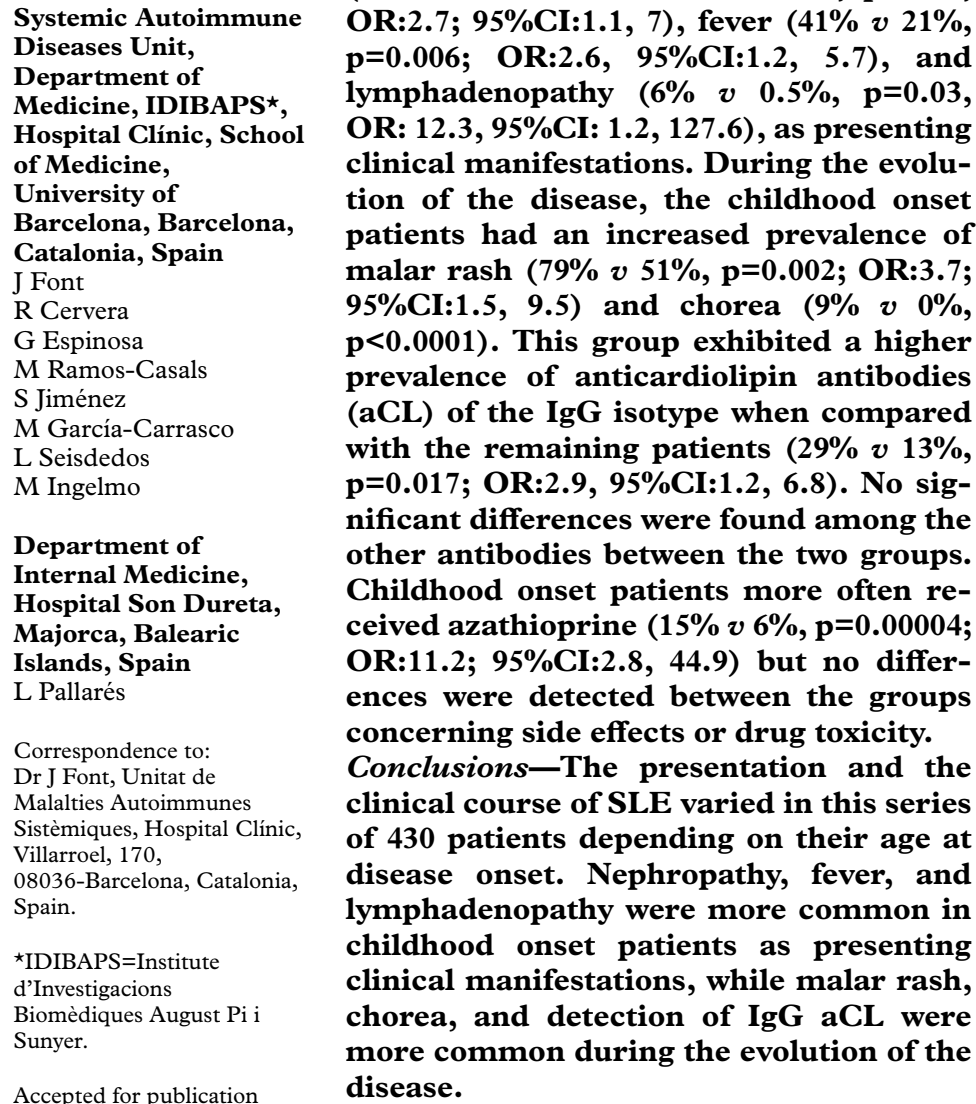

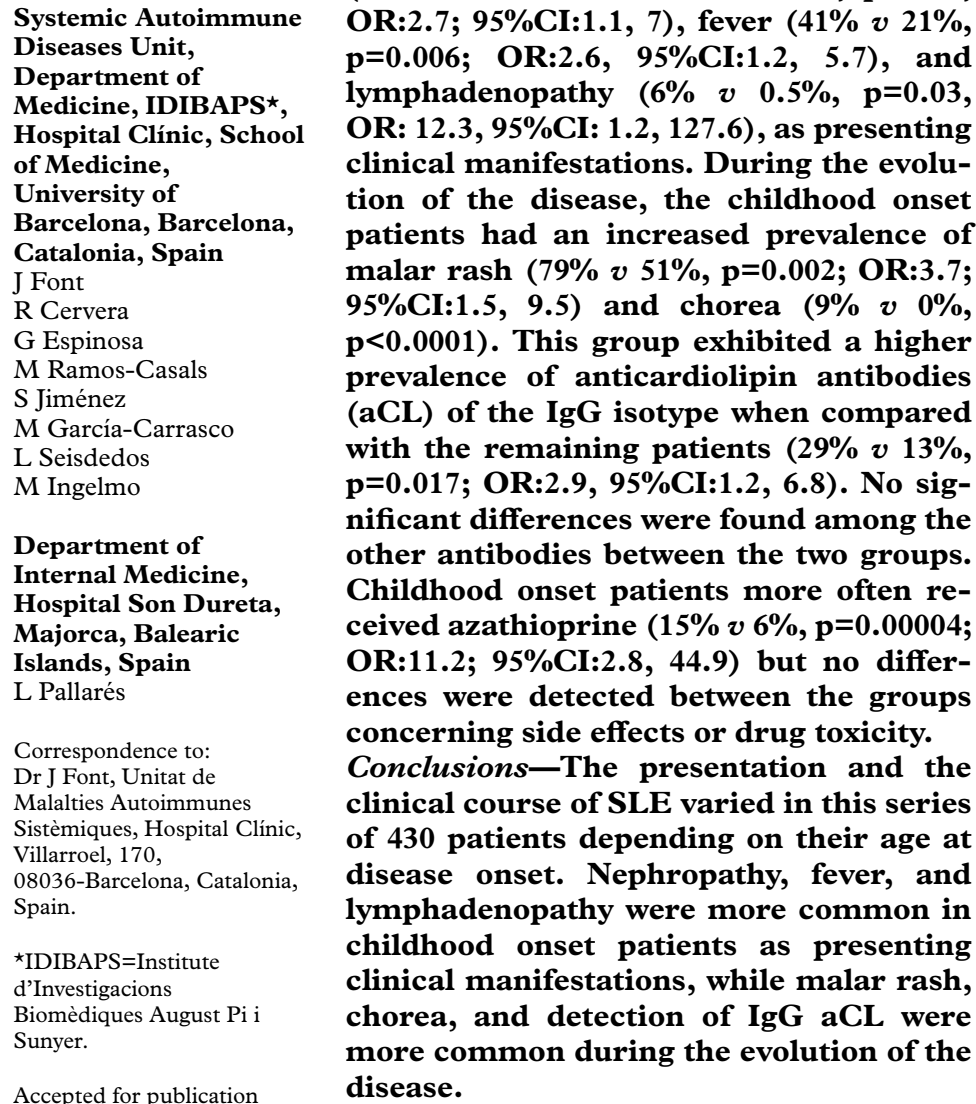

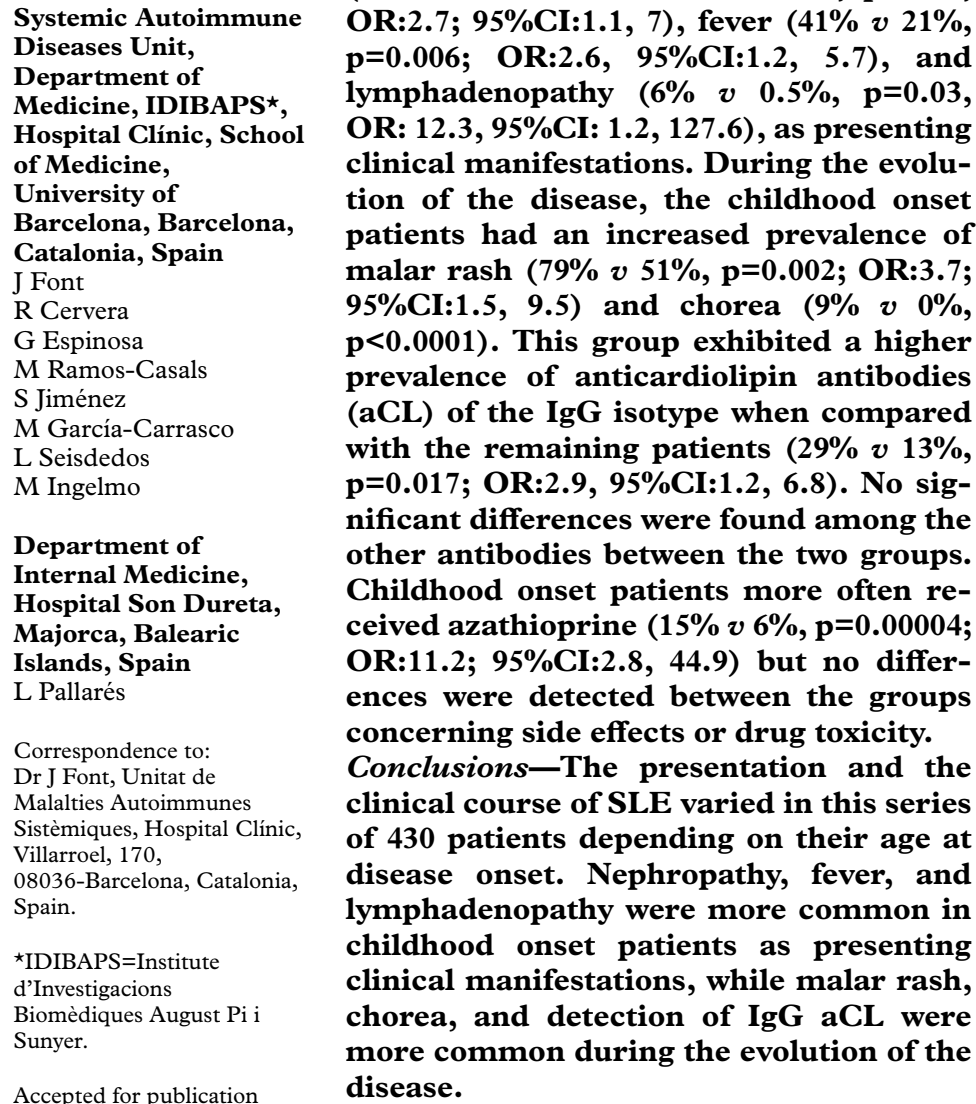

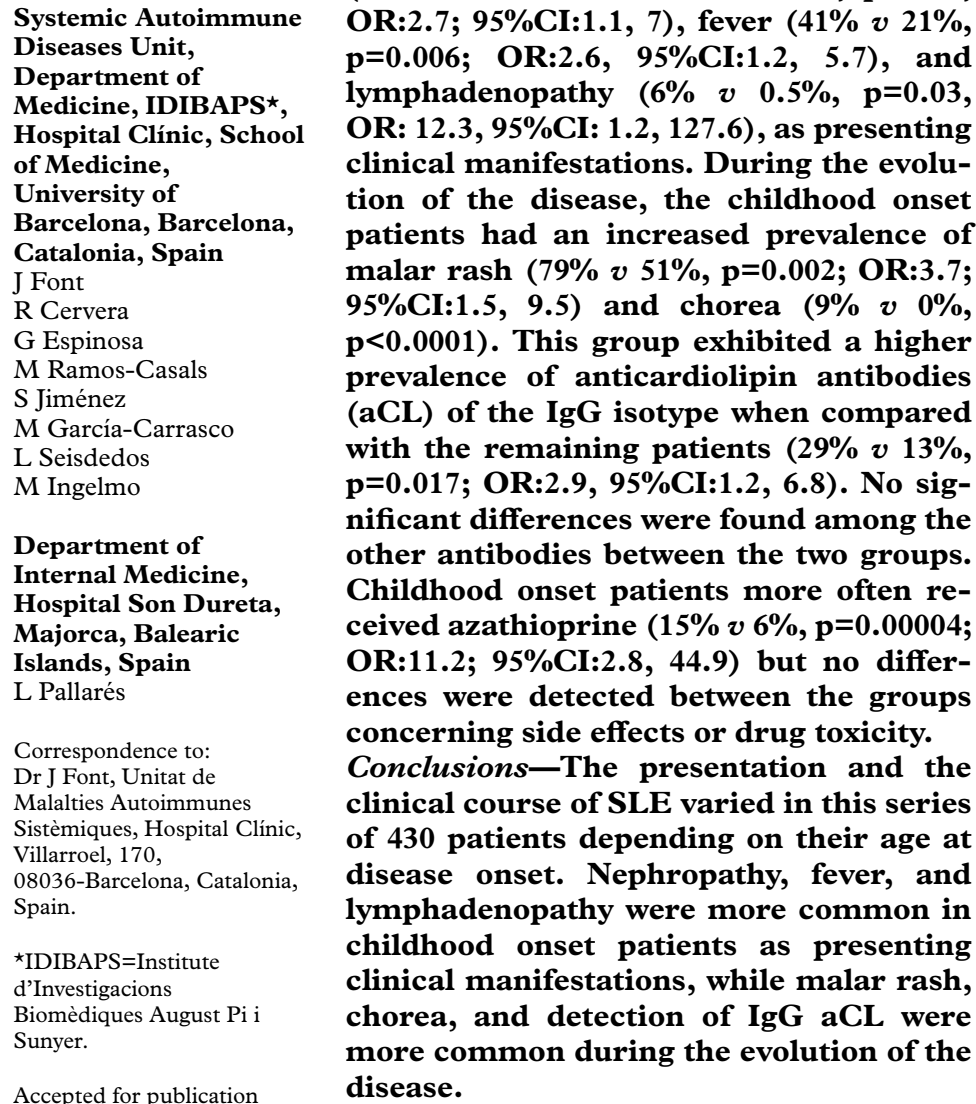

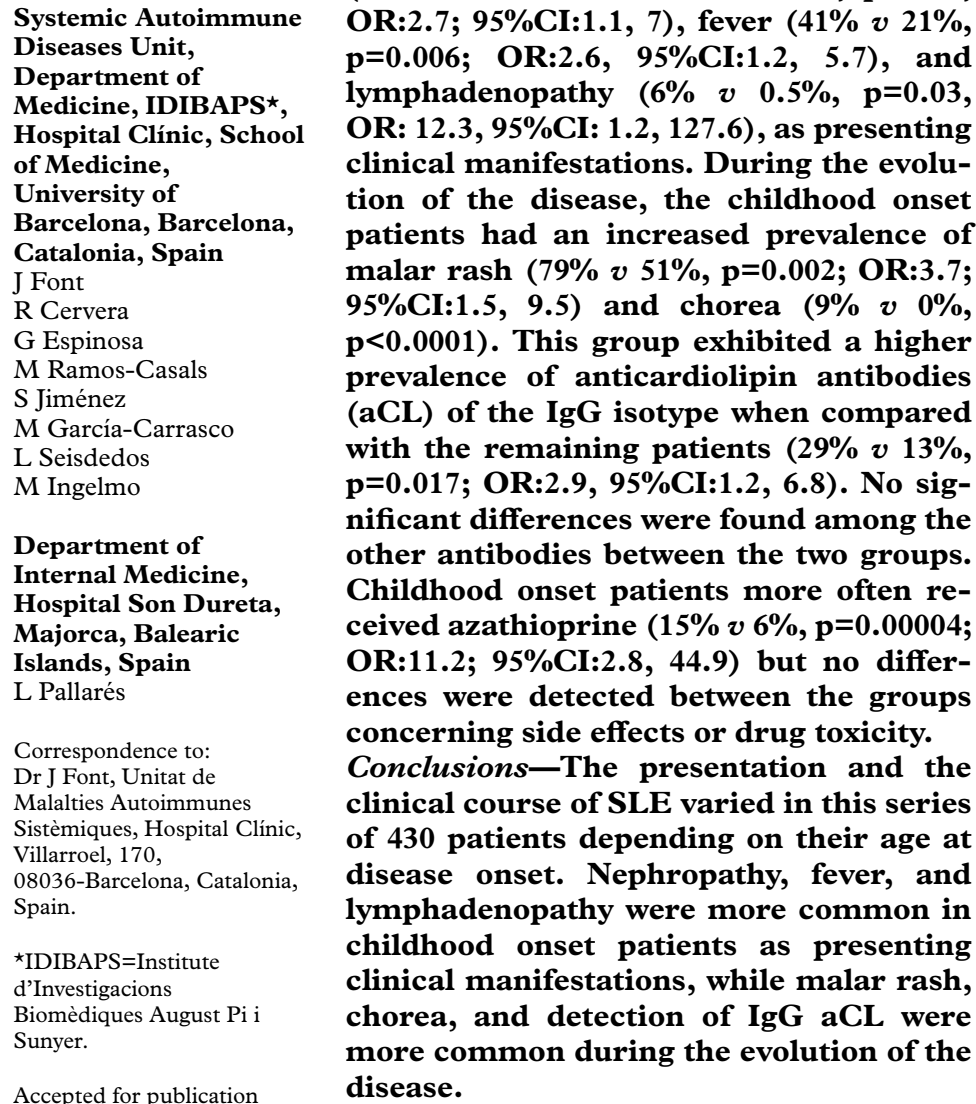

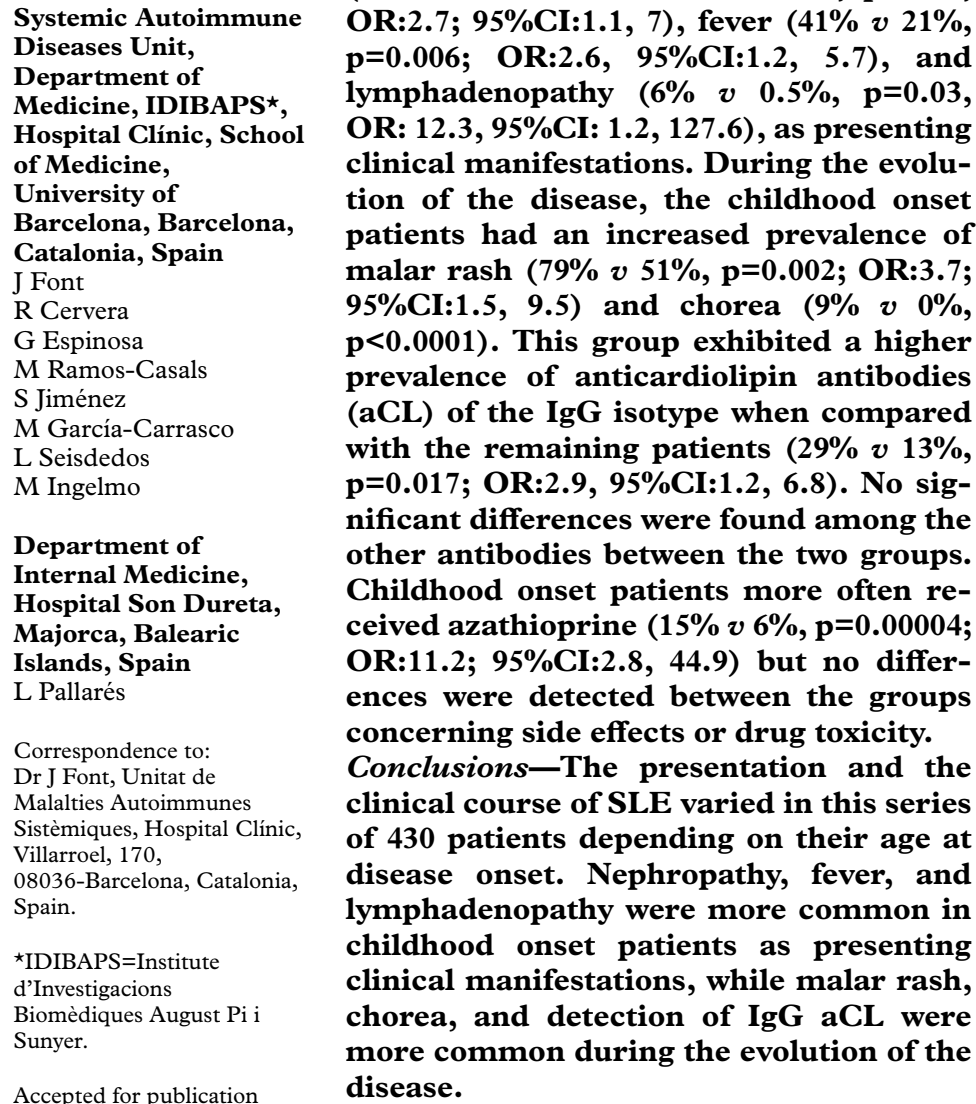

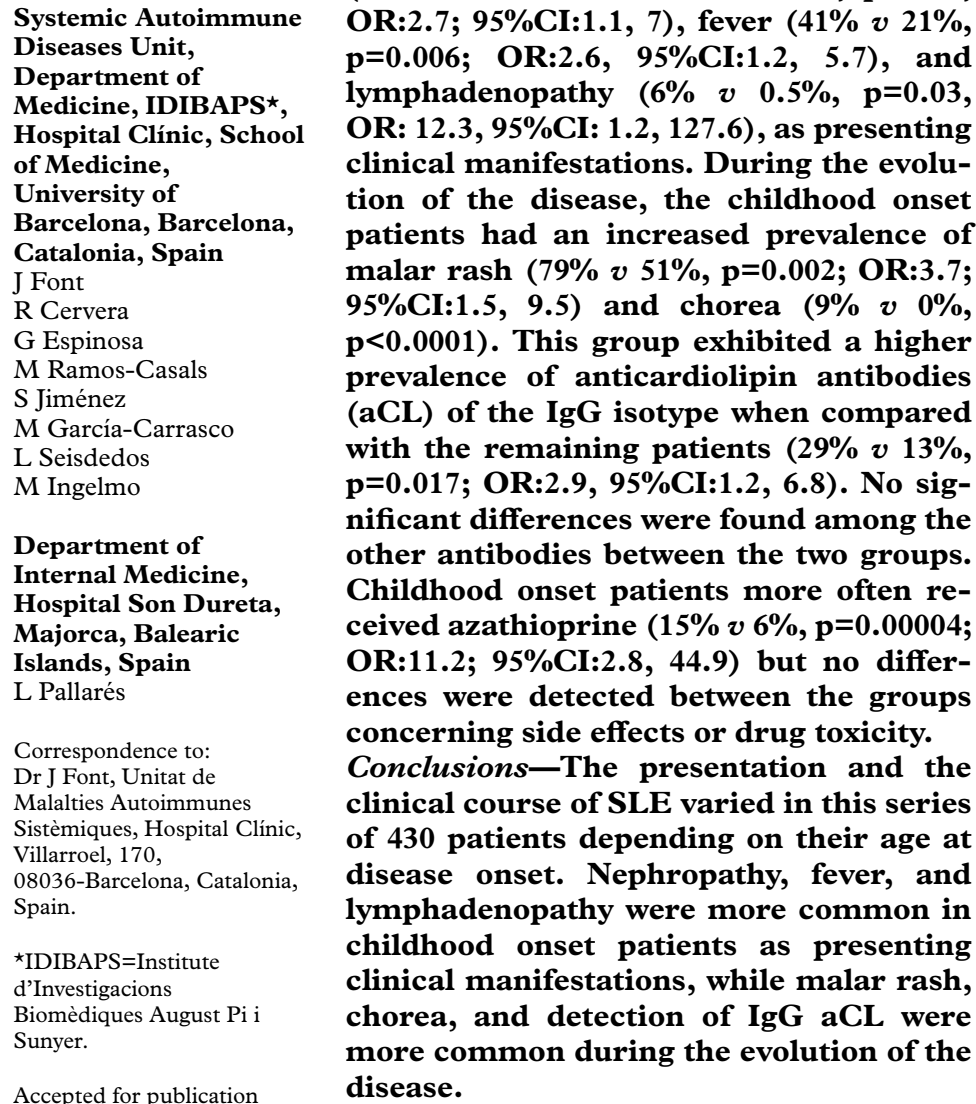

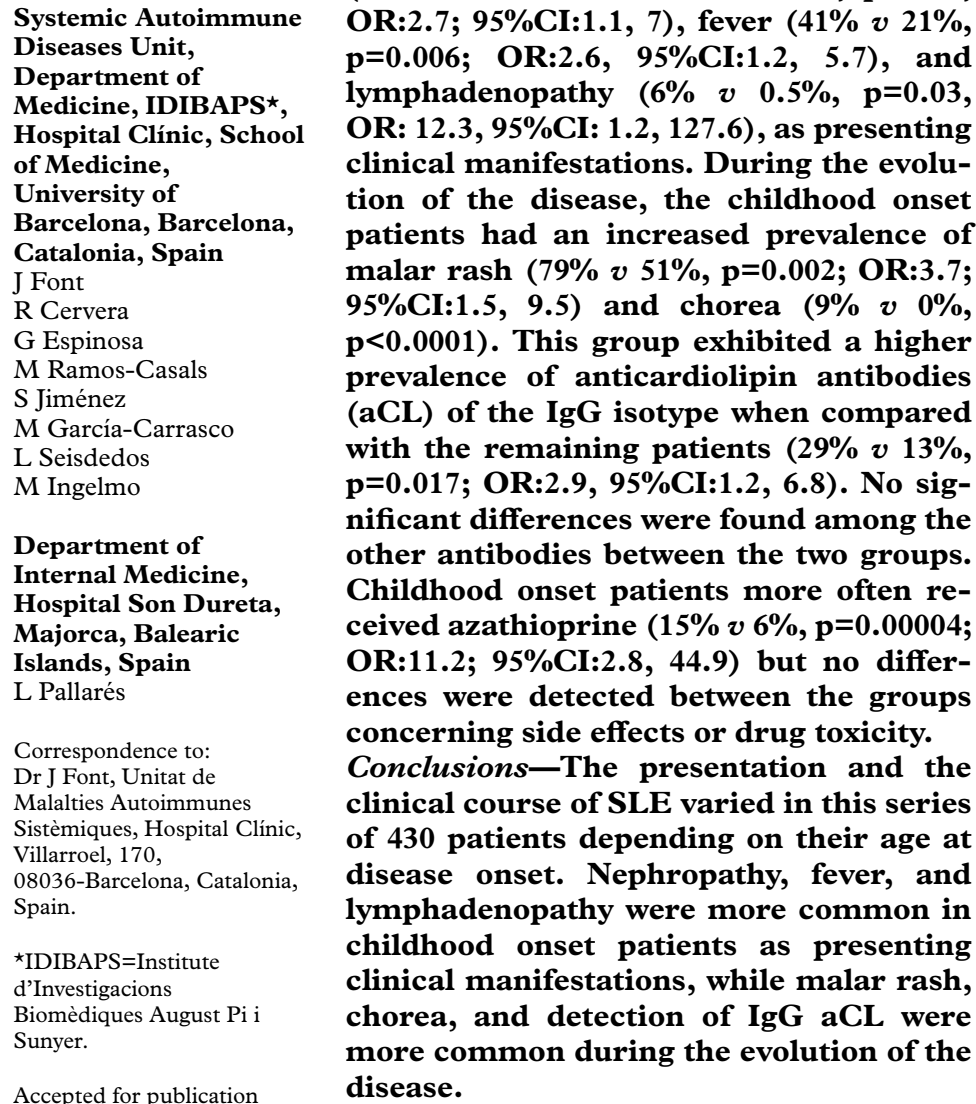

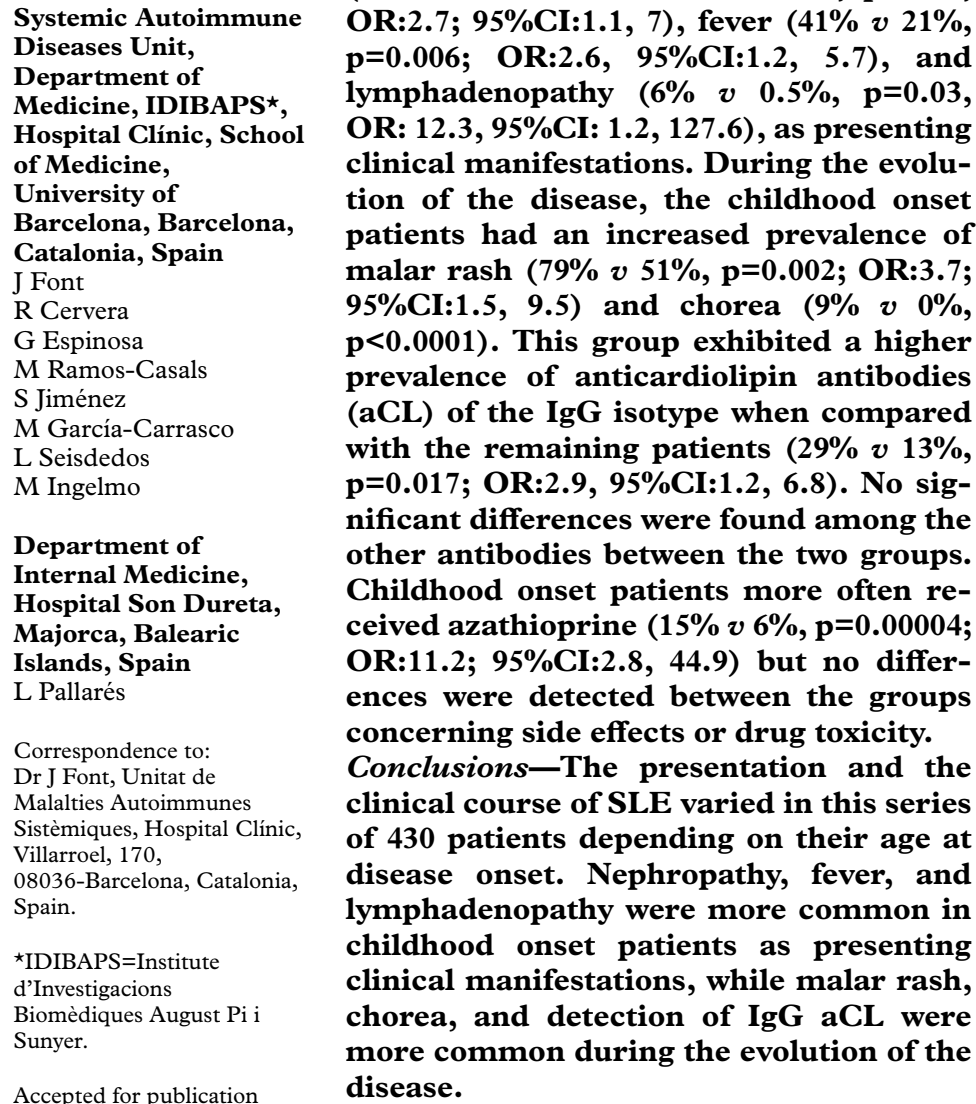

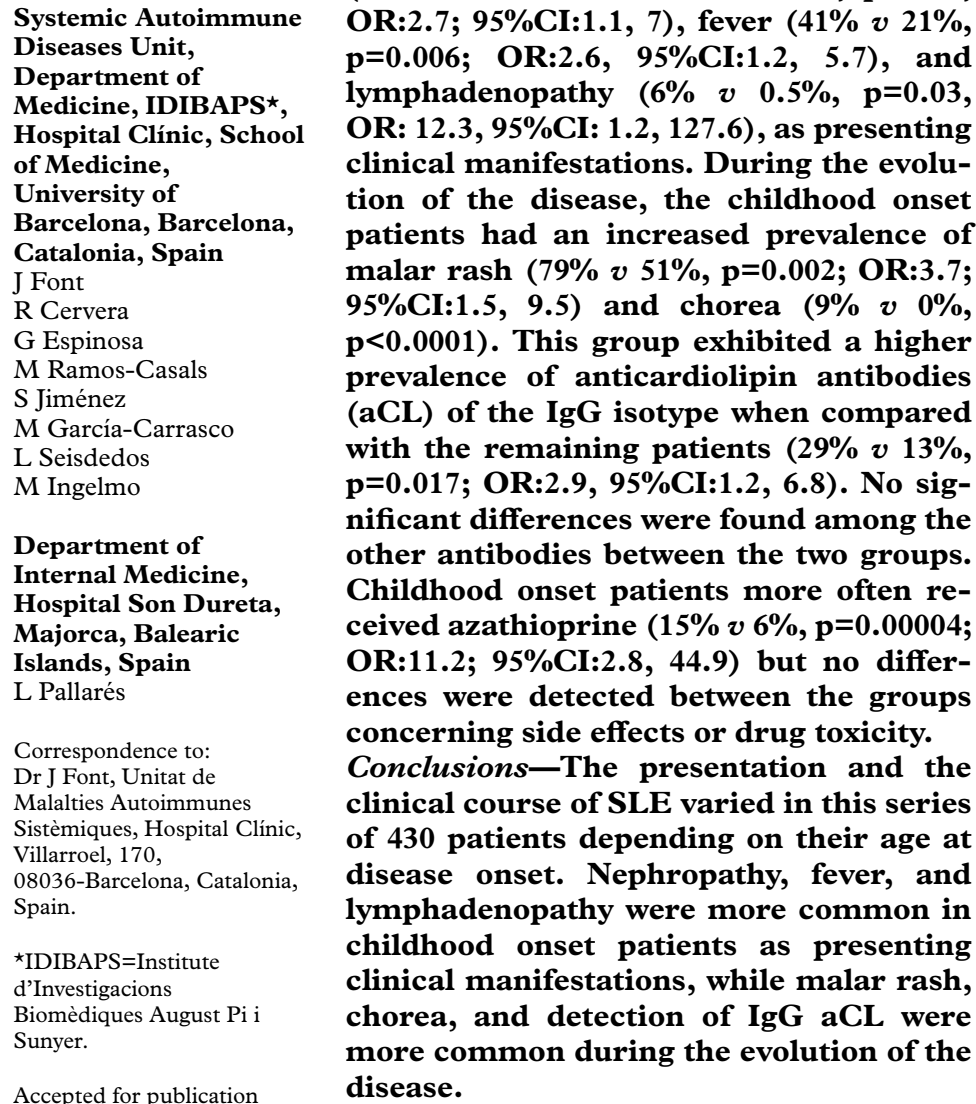

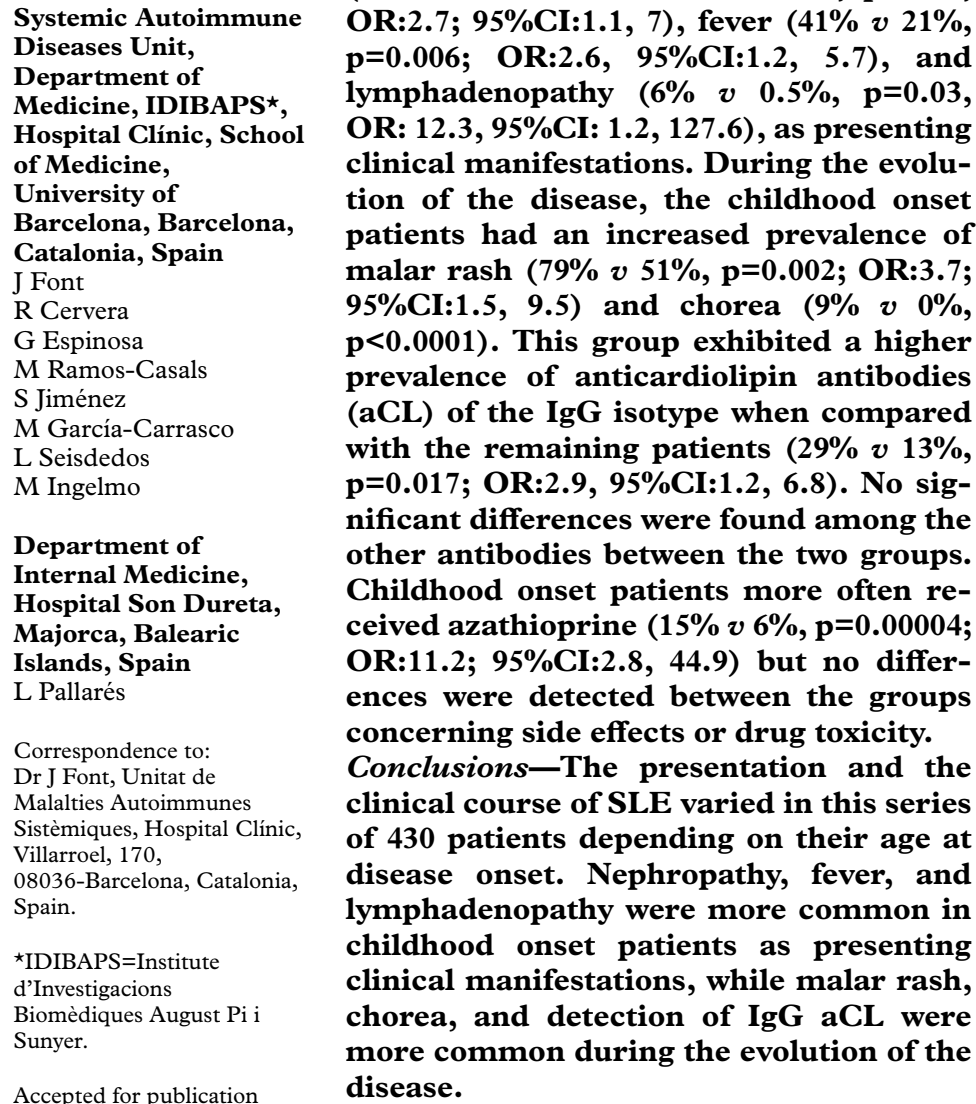

(Ann Rheum Dis 1998;57:456-459) 2 July 1998

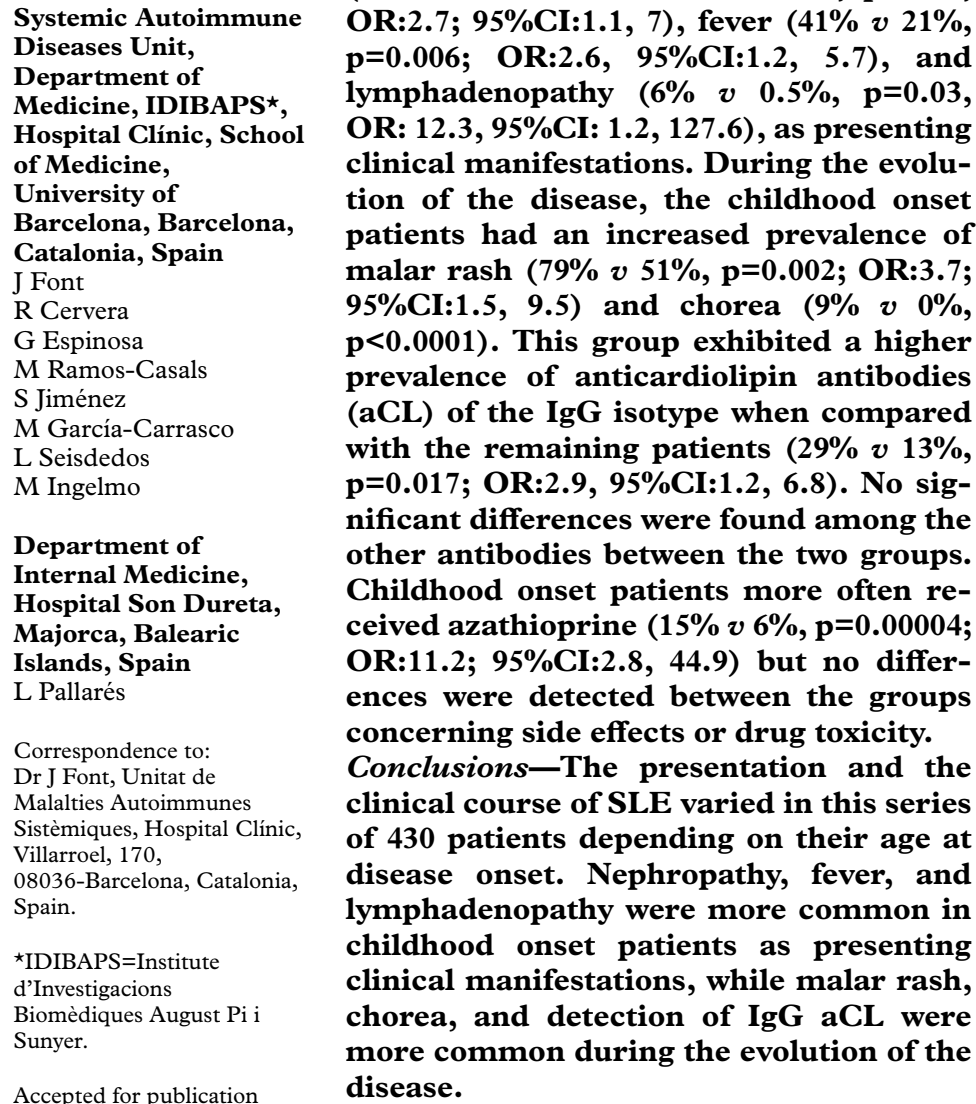

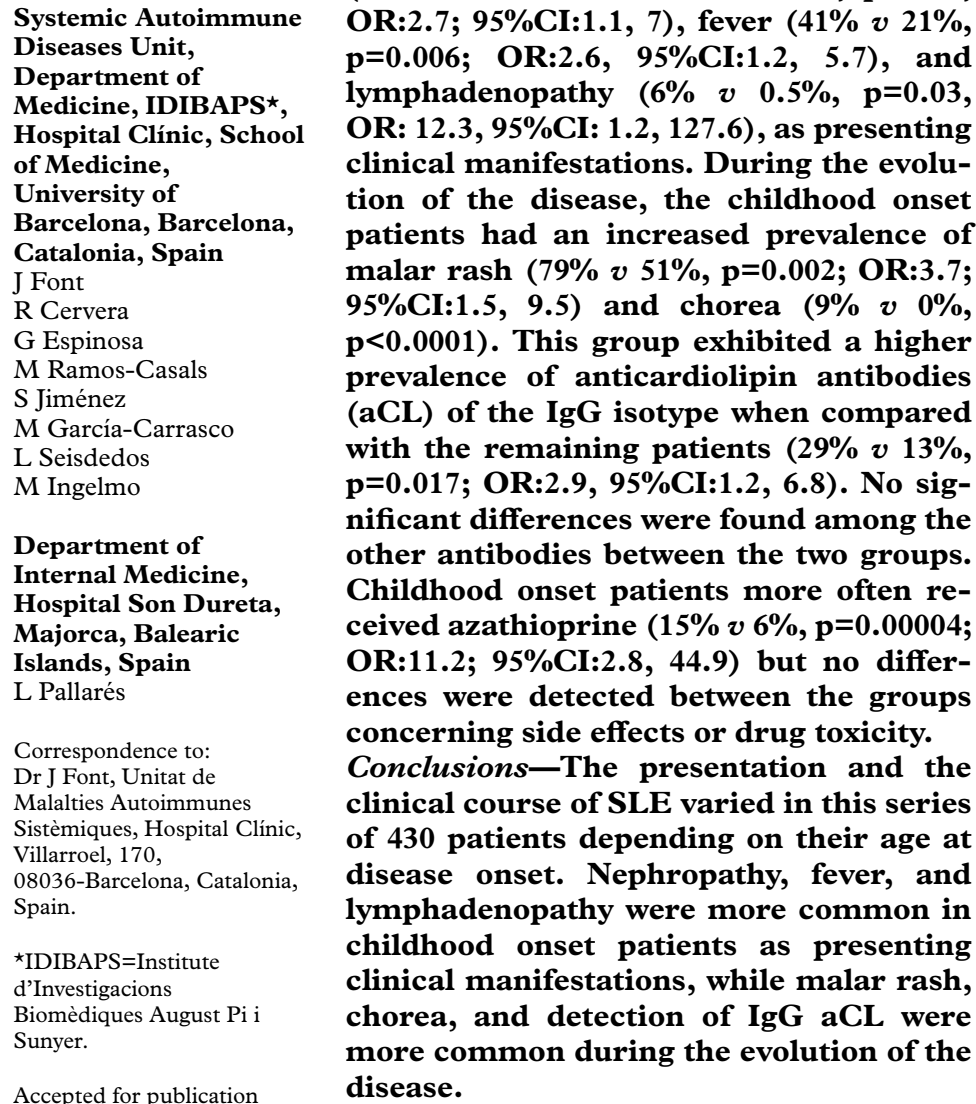

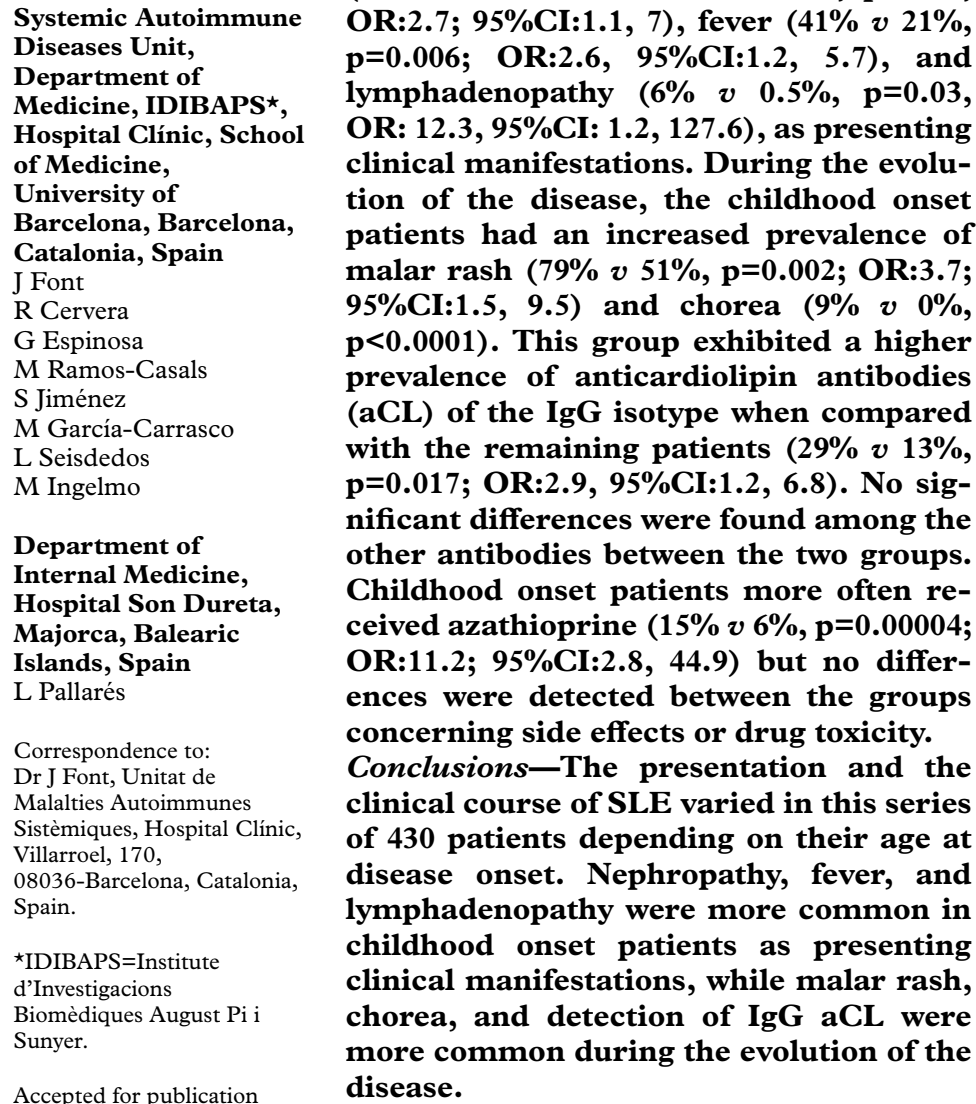

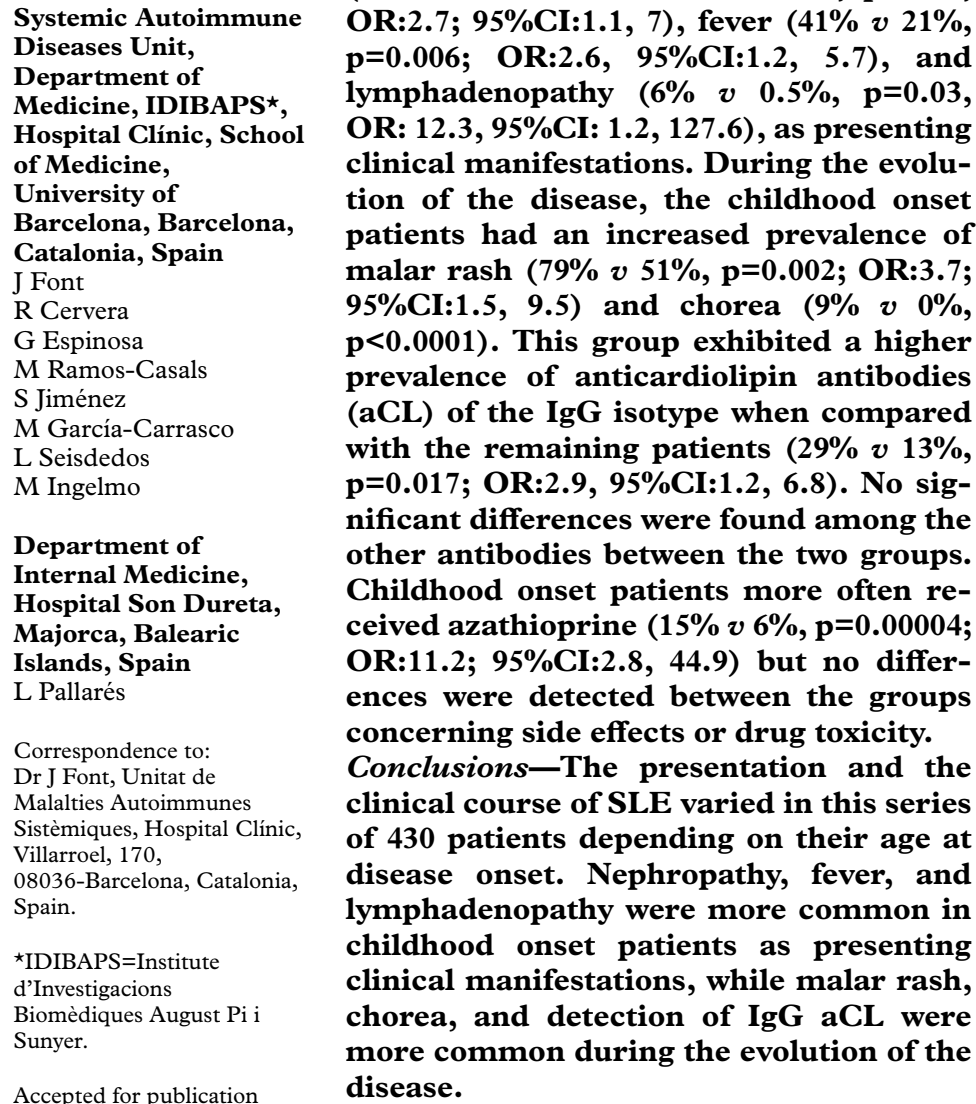


Table 1 Clinical manifestations at the onset of SLE in the childhood onset patients compared with the adult onset patients

\begin{tabular}{|c|c|c|c|}
\hline & $\begin{array}{l}\text { Childhood onset } \\
(n=34)\end{array}$ & $\begin{array}{l}\text { Adult onset } \\
(n=396)\end{array}$ & \\
\hline Manifestations & no (\%) & no (\%) & $p$ Value \\
\hline Malar rash & $15(44)$ & $139(35)$ & NS \\
\hline Discoid lesions & $0(0)$ & $13(3)$ & NS \\
\hline Subacute cutaneous lesions & $0(0)$ & $14(3)$ & NS \\
\hline Photosensitivity & $8(23)$ & $80(20)$ & NS \\
\hline Oral ulcers & $3(9)$ & $51(13)$ & NS \\
\hline Arthritis & $22(65)$ & $247(62)$ & NS \\
\hline Serositis & $4(12)$ & $51(13)$ & NS \\
\hline Nephropathy & $7(20)$ & $35(9)$ & 0.04 \\
\hline Neurological involvement & $0(0)$ & $26(6)$ & NS \\
\hline Thrombocytopenia & $4(12)$ & $35(9)$ & NS \\
\hline Haemolytic anaemia & $3(9)$ & $11(3)$ & NS \\
\hline Fever & $14(41)$ & $83(21)$ & 0.006 \\
\hline Raynaud's phenomenon & $4(12)$ & $62(16)$ & NS \\
\hline Livedo reticularis & $1(3)$ & $2(0.5)$ & NS \\
\hline Thrombosis & $0(0)$ & $3(1)$ & NS \\
\hline Myositis & $1(3)$ & $15(4)$ & NS \\
\hline Lung involvement & $0(0)$ & $5(1)$ & NS \\
\hline Chorea & $1(3)$ & $0(0)$ & NS \\
\hline Sicca syndrome & $0(0)$ & $2(0.5)$ & NS \\
\hline Lymphadenopathy & $2(6)$ & $2(0.5)$ & 0.03 \\
\hline
\end{tabular}

form. Salient features included in this protocol were: (1) age at onset of the disease, (2) age at diagnosis, defined as the age when the patient fulfilled four or more of the 1982 revised ARA criteria for the classification of SLE, (3) time of evolution of the disease, defined as the time from the onset until the present study, (4) clinical manifestations at the onset, (5) cumulative clinical manifestations during the evolution of the disease, and (6) laboratory features at diagnosis. Information collected into the protocol forms was transferred to a computerised database program (DBASE IV).

DEFINITION OF CLINICAL FEATURES

To minimise possible inter-observer bias, the variables of this protocol were carefully discussed by all the participating physicians on several occasions. The clinical manifestations evaluated in this protocol were defined according to the ARA glossary committee. ${ }^{8}$

LABORATORY STUDIES

Antinuclear antibodies (ANA) were determined by indirect immunofluorescence using

Table 2 Clinical manifestations during the evolution of SLE in the childhood onset patients compared with the adult onset patients

\begin{tabular}{lcccc}
\hline & $\begin{array}{c}\text { Childhood onset } \\
(n=34)\end{array}$ & \multicolumn{1}{c}{$\begin{array}{c}\text { Adult onset } \\
(n=396)\end{array}$} & \\
\cline { 2 - 2 } Manifestations & $n o(\%)$ & $n o(\%)$ & $p$ Value \\
\hline Malar rash & $27(79)$ & $203(51)$ & 0.002 \\
Discoid lesions & $5(15)$ & $17(4)$ & NS \\
Subacute cutaneous lesions & $1(3)$ & $25(6)$ & NS \\
Photosensitivity & $15(44)$ & $140(35)$ & NS \\
Oral ulcers & $13(38)$ & $100(25)$ & NS \\
Arthritis & $30(88)$ & $320(81)$ & NS \\
Serositis & $11(32)$ & $109(27)$ & NS \\
Nephropathy & $17(50)$ & $136(34)$ & NS \\
Neurological involvement & $9(26)$ & $63(16)$ & NS \\
Thrombocytopenia & $9(26)$ & $91(23)$ & NS \\
Haemolytic anaemia & $5(15)$ & $26(6)$ & NS \\
Fever & $21(62)$ & $170(43)$ & NS \\
Raynaud's phenomenon & $7(20)$ & $100(25)$ & NS \\
Livedo reticularis & $2(6)$ & $5(1)$ & NS \\
Thrombosis & $0(0)$ & $31(8)$ & NS \\
Myositis & $1(3)$ & $28(7)$ & NS \\
Lung involvement & $2(6)$ & $15(4)$ & NS \\
Chorea & $3(9)$ & $0(0)$ & $<0.001$ \\
Sicca syndrome & $3(9)$ & $61(15)$ & NS \\
Lymphadenopathy & $2(6)$ & $3(1)$ & NS \\
\hline
\end{tabular}

mouse liver as substrate and regarded as positive if higher than 1:100. Anti-dsDNA antibodies were determined with Farr's ammonium sulphate precipitation technique and considered as positive if higher than $7 \mathrm{U} / \mathrm{ml}$. Precipitating antibodies to extractable nuclear antigens (ENA), including $\mathrm{Ro}(\mathrm{SSA}), \mathrm{La}(\mathrm{SSB})$, U1-snRNP and Sm were detected by counterimmunoelectrophoresis using calf and rabbit thymus and human spleen extracts. Rheumatoid factor (RF) was detected by latex test and regarded as positive if higher than $25 \mathrm{UI} / \mathrm{ml}$. Anticardiolipin antibodies (aCL) of the IgG and IgM isotypes were measured by an ELISA method as described by Gharavi et al ${ }^{9}$ with minor modifications of our own. ${ }^{10}$ The results were expressed as negative or low, moderate, or high positive, according to the recommendations of the 1986 workshop on standardisation of the aCL test. ${ }^{11}$ The lupus anticoagulant (LA) activity was detected by coagulation assays in platelet free plasma obtained by double centrifugation following the recommendations of the subcommittee on LA of the Scientific and Standardisation Committee of the International Society of Thrombosis and Hemostasis. $^{12}$

\section{STATISTICAL ANALYSIS}

Conventional $\chi^{2}$ and Fisher's exact tests were used for analysing qualitative differences, and Student's $t$ test for comparison of means in large independent samples of similar variance. A $p<0.05$ value was taken to indicate statistical significance. When several independent variables appeared to have statistical significance in the univariate analysis, a logistic regression test was performed for multivariate analysis to rule out possible confounding variables. In this case, only those variables showing statistical significance in the multivariate analysis were considered as significant in the results of the study. The odds ratio (OR) was calculated for assessing the risk of appearance of each variable. A lower limit of the $95 \%$ confidence intervals (CI) that exceeded 1.0 was taken to indicate statistical significance in the case of positive association and and upper limit lower than 1.0 in the case of negative association. Results of the analysis of continuous variables are indicated as mean (SD). This statistical analysis was performed by means of the SPSS/PC 4.0 and EPISTAT programs using the information stored in the database program.

\section{Results}

\section{PATIENTS}

Thirty one $(91 \%)$ patients from the childhood onset group were female and three male $(9 \%)$ (ratio female/male, 10/1, with no difference compared with the adult onset group). Mean age of this group at disease onset was 11 years (range 5-14) compared with 32 years (15-48) for the remaining patients. Mean age at diagnosis of SLE of childhood onset patients was 14 years (range 6-28) compared with 34 years (15-85) for the adult onset patients. The interval between the time of onset and diagnosis was three years in the childhood onset group 
Table 3 Immunological findings at diagnosis of SLE in the childhood onset patients compared with the adult onset patients

\begin{tabular}{lcccc}
\hline & $\begin{array}{l}\text { Childhood onset } \\
(n=34)\end{array}$ & & $\begin{array}{l}\text { Adult onset } \\
(n=396)\end{array}$ & \\
\cline { 2 - 2 } Variable & $n o(\%)$ & & $n o(\%)$ & V Value \\
\hline Antinuclear antibodies & $33(97)$ & & $388(97)$ & NS \\
High anti-dsDNA & $29(85)$ & & $360(90)$ & NS \\
Anti-Ro (SSA) & $5(14)$ & & $82(20)$ & NS \\
Anti-La (SSB) & $2(5)$ & & $26(6)$ & NS \\
Anti-U1-snRNP & $4(11)$ & & $50(12)$ & NS \\
Anti-Sm & $4(11)$ & & $49(12)$ & NS \\
Rheumatoid factor & $2(5)$ & & $51(12)$ & NS \\
IgG anticardiolipin antibodies & $10(29)$ & & $50(13)$ & 0.017 \\
IgM anticardiolipin antibodies & $6(18)$ & & $34(9)$ & NS \\
Lupus anticoagulant & $6(18)$ & & $57(14)$ & NS \\
\hline
\end{tabular}

compared with two years in the adult onset group (difference not significant). Mean time of evolution of the disease in the childhood onset group was 85 months (range 1-264) and in the adult onset group was 73 months (1-528) (difference not significant).

CLINICAL MANIFESTATIONS

Table 1 shows the presenting clinical manifestations for patients with disease onset before or after age 14 . The childhood onset patients more often had nephropathy $(20 \% v 9 \%$ in adult onset SLE, $\mathrm{p}=0.04$; OR:2.7; 95\% CI:1.1, 7 ), fever $(41 \%$ v $21 \%, \mathrm{p}=0.006$; OR:2.6, $95 \% \mathrm{CI}: 1.2,5.7)$, and lymphadenopathy $(6 \% v$ $0.5 \%, \mathrm{p}=0.03$, OR: $12.3,95 \% \mathrm{CI}: 1.2,127.6)$. During the evolution of the disease (table 2), the childhood onset patients more often presented malar rash $(79 \%$ v $51 \%, \mathrm{p}=0.002$; OR:3.7; 95\%CI: $1.5,9.5)$ and chorea (9\% v $0 \%, \mathrm{p}<0.001)$. The frequency of other clinical features, including serositis, central nervous system manifestations and pulmonary disease, did not differ significantly between the groups.

IMMUNOLOGICAL FEATURES

Table 3 gives the main immunological findings of childhood onset patients. This group more frequently exhibited a positive level of anticardiolipin antibodies (aCL) of the IgG isotype when compared with the remaining patients

Table 4 Treatments prescribed for SLE during the study

\begin{tabular}{|c|c|c|c|}
\hline & $\begin{array}{l}\text { Childhood onset } \\
(n=34)\end{array}$ & $\begin{array}{l}\text { Adult onset } \\
(n=396)\end{array}$ & \\
\hline Treatments & no (\%) & no (\%) & p Value \\
\hline NSAID & $30(88)$ & $321(81)$ & NS \\
\hline Antimalarials & $29(85)$ & $323(82)$ & NS \\
\hline Oral corticosteroids & $32(94)$ & $332(84)$ & NS \\
\hline Pulse corticosteroids & $1(3)$ & $3(1)$ & NS \\
\hline Oral cyclophosphamide & $3(9)$ & $17(4)$ & NS \\
\hline Azathioprine & $5(15)$ & $6(2)$ & 0.00004 \\
\hline Haemodyalisis & $0(0)$ & $1(0)$ & NS \\
\hline Antiaggregants & $2(6)$ & $9(2)$ & NS \\
\hline Anticoagulants & $0(0)$ & $16(4)$ & NS \\
\hline
\end{tabular}

NSAID: Non-steroidal anti-inflammatory drugs.

Table 5 Main side effects because of the treatments prescribed for SLE during the study

\begin{tabular}{|c|c|c|c|}
\hline & $\begin{array}{l}\text { Childhood onset } \\
(n=34)\end{array}$ & $\begin{array}{l}\text { Adult onset } \\
(n=396)\end{array}$ & \\
\hline Side effects & no (\%) & no (\%) & $p$ Value \\
\hline Infections & $6(18)$ & $39(10)$ & NS \\
\hline Osteoporosis & $2(6)$ & $7(2)$ & NS \\
\hline Avascular necrosis & $1(3)$ & $12(3)$ & NS \\
\hline Retinopathy & $0(0)$ & $2(0)$ & NS \\
\hline
\end{tabular}

$(29 \%$ v 13\%, p=0.017; OR:2.9, 95\% CI: 1.2 , 6.8). No significant differences were found among the other antibodies between the two groups.

TREATMENT AND SIDE EFFECTS

Table 4 summarises the main SLE treatments prescribed during the study period. Childhood onset patients more often received azathioprine when compared with the remaining patients (15\% v 6\%, $\mathrm{p}=0.00004$; OR: $11.2 ; 95 \% \mathrm{CI}: 2.8$, 44.9). No differences were detected between the groups concerning side effects or drug toxicity (table 5).

\section{Discussion}

There have been several studies dealing with childhood onset SLE and their results suggested that age at onset modifies the expression of the disease in terms of clinical presentation, pattern of organ involvement, and serological findings. ${ }^{2-6}{ }^{13-33}$ However, the true prevalence of childhood onset SLE among the SLE population is unknown. One of the reasons is that there is not strict definition of childhood onset SLE. The most often used cut off ages are 14 or 16 years at onset of disease $\mathrm{e}^{14-18}$ or at diagnosis. ${ }^{1920}$ However several studies use a higher or lower cut off age. In our series, 34 $(8 \%)$ of 430 patients with SLE developed the initial manifestations clearly attributable to the disease before the age of 14 . In other series, the prevalence of childhood SLE in children younger than 16 is nearly $15 \%$. $^{14}{ }^{15}$

The onset of SLE is rare before the age of 5 years. ${ }^{13}$ In our series, one patient presented clinical manifestations of SLE at the age of 5 years but none of our patients presented these manifestations before this age.

The female to male ratio in adult onset SLE is generally found to be slightly more than 10:1. A higher proportion of men is often reported in childhood onset SLE in some series. ${ }^{1420212627}$ but not in others. ${ }^{1822}{ }^{28}$ In our series, men represented $9 \%$ of the cases of childhood onset SLE with a female to male ratio similar to that in the adult onset SLE.

Although there are many previous publications of paediatric SLE, the strength of this study is that, unlike many others, it compares children and adults from the same clinic population. Comparison of the clinical features at onset between childhood onset and adult onset patients reveals both similarities and important differences. The frequency of skin, joint, serositis, and haematological disease was similar in both groups and correlates with previous reports. ${ }^{20}$ However, childhood onset SLE patients had more frequently renal involvement, fever, and lymphadenopathy, as has also been reported by other authors. ${ }^{21}$

Nephropathy is often described in childhood onset SLE, ${ }^{22-24} 262732$ although this manifestation has been more frequently described in North American series-especially in children with a Central and South American Hispanic background ${ }^{33}$ - than in European patients. ${ }^{1}$ In our cohort, which includes all the patients diagnosed as having SLE in our areas, 20\% of childhood onset SLE patients presented 
nephropathy as initial clinical manifestation. Severity in this disease is closely related to renal involvement. ${ }^{62633}$ Thus, SLE pattern is generally more severe in children than in adults. This inverse correlation between the severity of the disease and the age of diagnosis has been noted since the earlier series. ${ }^{25}$ However, a striking finding is the additional organ system involvement over the course of follow up in both adults and children. As time goes on, prevalence of renal involvement is similar in both groups of age. The main significant differences during the evolution of the disease are the more common prevalence of malar rash and chorea in the childhood onset group, correlating with previous reports. ${ }^{15}$ It is of note that the treatment given to children was similar to that given to adults, except for a more common use of azathioprine in childhood onset patients. No differences were detected between the groups concerning side effects or drug toxicity.

Comparison of the autoantibody profiles of adults and childhood cases shows a similar frequency of increased anti-dsDNA and positive ANA in both groups. These data are in contrast with previous reports ${ }^{1431}$ in which the frequency of these antibodies is higher in childhood than adult cases. The only significant difference between the two groups is the higher presence of IgG aCL in children than in adult patients. However, there was not any case of thrombosis in childhood onset during the follow up period.

We conclude that the presentation and the clinical course of SLE varied in our series of 430 patients depending on their age at disease onset. Nephropathy, fever, and lymphadenopathy were more common in childhood onset patients as presenting clinical manifestations, while malar rash, chorea, and detection of IgG aCL were more common during the evolution of the disease.

1 Cervera R, Khamashta MA, Font J, Sebastiani GD, Gil A, Lavilla P, et al. Systemic lupus erythematosus: Clinical and immunologic patterns of disease expression in a cohort of 1,000 patients. Medicine (Baltimore) 1993;72:113-24.

2 Nepom BS, Schaller JG. Childhood systemic lupus erythematosus. Prog Clin Rheumatol 1984;1:33-69.

3 Tucker LB, Menon S, Isenberg DA. Systemic lupus in children: daughter of the Hydra? Lupus 1995;4:83-5.

4 Schaller J. Lupus in childhood. Clin Rheum Dis 1982;8: 219-28.

5 Ting CK, Hsieh KH. A long term immunological study of childhood onset systemic lupus erythematosus. Ann Rheum Dis 1992;51:45-51.

6 Rosenberg AM. Systemic lupus erythematosus in children. Springer Semin Immunopathol 1994;16:261-79.

7 Tan EM, Cohen AS, Fries JF, Masi AT, McShane DJ, Rothfield NF, et al. The 1982 revised criteria for the field $\mathrm{NF}$, et al. The 1982 revised criteria for the classification of systemic

8 American Rheumatism Association glossary committee. Signs and symptoms. Dictionary of the Rheumatic Disease $1982 ; 1: 1-80$
9 Gharavi AE, Harris EN, Asherson RA, Hughes GRV. Anticardiolipin antibodies: Isotype distribution and phospholipid specificity. Ann Rheum Dis 1987;46:1-6.

10 Cervera R, Font J, López-Soto A, Casals F, Pallarés L, Bové A, et al. Isotype distribution of anticardiolipin antibodies in systemic lupus erythematosus: prospective analysis of 100 patients. Ann Rheum Dis 1990;49:109-13.

11 Harris EN, Ghravi AE, Patel SP, Hughes GRV. Evaluation of the anti-cardiolipin antibody test: report of an international workshop held 4 April 1986. Clin Exp Immunol 1987;68:215-22.

12 Brandt JT, Triplett DA, Alving B, Scharrer I. Criteria for the diagnosis of lupus anticoagulants: an update. Thromb Haemost 1995;74:1185-90.

13 Dubois EL, Tuffanelli DL. Clinical manifestations of systemic lupus erythematosus. Computer analysis of 520 cases. JAMA 1964;190:104-13.

14 Costallat LTL, Coimbra AMV. Systemic lupus erythematosus: clinical and laboratory aspects to age at disease onset. Clin Exp Rheumatol 1994;12:603-7.

15 Huong DLT, Weschler B, Piette JC, Cacoub P, Sauvaget F, Papo T, et al. Clinical manifestations and outcome of chilhood systemic lupus erythematosus: a retrospective study of 50 cases. Eur J Int Med 1993; 4:15-22.

16 Hashimoto H, Tsuda H, Hirano T, Takasaki Y, Matsumoto T, Hirose S. Differences in clinical and immunological findings of systemic lupus erythematosus related to age. J Rheumatol 1987;14:497-501.

17 El-Garf A, Salah S. Juvenile systemic lupus erythematosus among Egyptian children. J Rheumatol 1990;17:1168-70.

18 Pande I, Sekharan NG, Kailash S, Uppal SS, Singh RR, Kumar A, et al. Analysis of clinical and laboratory profile in Indian chilhood systemic lupus erythematosus and its comparison with SLE in adults. Lupus 1993;2:83-7.

19 Walravens PA, Chase HP. Prognosis of childhood systemic lupus erythematosus. Am J Child 1976;130:941-5.

20 Tucker LB, Menon S, Schaller JG, Isenberg DA. Adult- and childhood-onset systemic lupus erythematosus: A comparison of onset, clinical features, serology, and outcome. Br J Rheumatol 1995;34:866-72.

21 Meislin AG, Rothfield N. Systemic lupus erythematosus in childhood. Pediatrics 1989;83:235-9.

22 Glidden RS, Mantzouranis EC, Borel Y. Systemic lupus erythematosus in childhood: clinical manifestations and improved survival in 55 patients. Clin Immunol Immunopathol 1983;29:196-210.

23 Caeiro F, Michielson FMC, Bernstein R, Hughes GRV Ansell BM. Systemic lupus erythematosus in childhood. Ann Rheum Dis 1981;40:325-31.

24 Celermeyer DS, Thorner PS, Baumal R, Arbus GS. Sex differences in childhood lupus nephritis. Am J Dis Child 1984;138:586-8.

25 McCombs RP, Patterson JF. Factors influencing the course and prognosis of systemic lupus erythematosus. N Engl J Med 1959;260:1195-204.

26 King KK, Kornreich HK, Bernstein BH, Singsen BH, Hanson $\mathrm{V}$. The clinical spectrum of systemic lupus erythematosus in childhood. Arthritis Rheum 1977;20:287-94.

27 Cassidy JT, Sullivan DB, Petty RE, Ragsdale C. Lupus nephritis and encephalopathy: Prognosis in 58 children. Arthritis Rheum 1977;20:315-22.

28 Lehman TJA, McCurdy DK, Bernstein BH, King KK, Hanson V. Systemic lupus erythematosus in the first decade of life. Pediatrics 1989;83:235-9.

29 Yancey CL, Doughty RA, Athreya BH. Central nervous system involvement in childhood systemic lupus erythematosus. Arthritis Rheum 1981;24:1389-95.

30 Shergy WJ, Kredich DW, Pisetsky DS. Patterns of autoantibody expression in pediatric and adult systemic lupus erythematosus. J Rheumatol 1989;16:1329-34.

31 Ward MM, Dawson DV, Kredich DW, Pisetsky DS. Expression of IgM and IgG autoantibodies in pediatric and adult systemic lupus erythematosus. Clin Immunol Immunopathol 1990;55:273-84

32 Barron KS, Silverman DE, Gonzales J, Reveille J. Clinical, serologic and immunogenetic studies in childhood-onset systemic lupus erythematosus. Arthritis Rheum 1993;3: 340-8.

33 Tejani A, Nicastri AD, Chen CK, Fikrig S, Gurumurthy K. Lupus nephritis in Black and Hispanic children. Am J Dis Child 1983;137:481-4. 